\title{
El viaje histórico de la fundación hacia su institucionalización como entidad jurídica corporativa em la Civilización Romana
}

\author{
The historical trip of the foundation towards \\ his institutionalization like law corporate \\ entity in the Roman Civilization
}

Guillermo Suárez Blázquez ${ }^{1}$

\section{RESUMEN}

No cabe duda de la profunda interrelación entre la creación romana de las personas jurídicas y el desarrollo económico y financiero del mundo moderno, a través de las compañías navieras y financieras, corporaciones industriales, bancarias y los entes administrativos. Esta interrelación también es perceptible en las entidades jurídicas filantrópicas personificadas como fundaciones. Así, la C.E de 1978 establece en su artículo 34.1 "Se reconoce el derecho de fundación para fines de interés general, con arreglo a la ley". En su virtud ha sido promulgada la Ley estatal ${ }^{2}$ 50/ 2002 de 26 de Diciembre, de Fundaciones, que establece en su artículo 2: "Son fundaciones las organizaciones constituidas sin fin de lucro que, por voluntad de sus creadores, tiene afectado de modo duradero su patrimonio a la realización de los fines de interés general". Una vez definida la institución, el artículo 4 de la misma norma consagra la personalidad jurídica de aquélla: "Las fundaciones tendrán personalidad jurídica desde la inscripción de la escritura pública de su constitución en el correspondiente registro de fundaciones". De este modo nuestro legislador distingue dos instituciones diferentes. Por una parte la fundación como institución que persigue fines no lucrativos mediante la voluntad unilateral de un instituyente. Por otra su personificación como ente corporativo. Personificación, que desde un punto de vista histórico jurídico, es el fruto de un largo periodo evolutivo. En esta dirección, nuestro estudio se dirige a analizar el proceso histórico jurídico que permitió el nacimiento de las fundaciones y su posterior desenvolvimiento como organizaciones o entes corporativos autónomos, dotados de facultades propias de la personalidad jurídica, vinculados al cumplimiento de una voluntad unilateral colectiva y perpetua, sin ánimo de lucro.

\footnotetext{
${ }^{1}$ Catedrático Acreditado de Derecho Romano de la Facultad de Derecho, Campus de Ourense de la Universidade de Vigo - España.

2 Las Comunidades autónomas también tienen competencia legislativa en materia de fundaciones. Se aplicará la ley estatal en aquellas CCAA. que no tengan asumida la competencia, o no tengan ley autonómica propia, siempre que la fundación opere exclusivamente en su territorio. Si la fundación desarrolla sus actividades en varias CCAA, o en todo el territorio nacional se aplicará, en todo caso, la legislación del Estado (Ley 50/2002).
} 


\title{
PALABRAS CLAVES
}

Fundación - corporación, piae causae.

\begin{abstract}
It does not fit doubt of the deep interrelationship between the Roman creation of the legal persons and the economic and financial development of the modern world, across the shipping and financial companies, industrial, bank corporations and the administrative entities. This interrelationship also is perceptible in the philanthropic legal entities personified as foundations. His way, the C.E of 1978 establishes in his article $34.1 "$ the right of foundation is recognized for ends of general interest, in accordance with the law". In his virtue the state Law has been promulgated 50/2002 of December 26 of Foundations, which it establishes in his article 2: They are foundations the organizations constituted without end of profit that, for will of his creators, has his heritage concerned in a lasting way the accomplishment of the ends of general interest ". Once defined the institution, the article 4 of the same norm dedicates the juridical personality of that one: "The foundations will have juridical personality from the inscription of the public writing of his constitution in the corresponding record of foundations". Thus our legislator distinguishes two different institutions. On one hand the foundation like institution that chases not lucrative ends by means of the unilateral will of the instituting one. For other one his personification like corporate entity. Juridical personification, which from a historical juridical point of view, is the fruit of a long evolutionary period. In this direction, our study directs for him to analyze the historical juridical process that allowed the birth of the foundations and his later development as organizations or corporate autonomous entities provided with own powers of the juridical personality, linked to the fulfillment of a unilateral collective and perpetual non-profit-making will.
\end{abstract}

\section{KEYWORDS}

Corporate Charity, piae causae.

\section{INTRODUCCIÓN}

Tras una evolución histórica larga y compleja, los ordenamientos jurídicos modernos se basan en la existencia de dos posibles sujetos de derechos subjetivos: la persona física, el individuo humano, la persona natural, capaz de expresar una voluntad propia e individualizada, y las personas jurídicas, también denominadas sociales, colectivas o ficticias. En efecto, aunque no puede negarse que el Derecho es una creación humana al servicio del ser humano, en último término el único y verdadero sujeto, es también cierto que existen intereses colectivos y fines humanos de carácter social que exigen una actividad que excede de las posibilidades de un solo hombre. Esta necesidad de proteger la colaboración entre personas, en orden a la consecución de fines generales, se traduce en el mundo del Derecho en el reconocimiento de las personas jurídicas.

No cabe duda, por tanto, de la profunda interrelación entre la creación romana de las personas jurídicas y el desarrollo económico y financiero del mundo moderno, a través de las compañías navieras y financieras, corporaciones industriales, bancarias y los entes 
administrativos. Esta interrelación también es perceptible en las entidades jurídicas filantrópicas personificadas como fundaciones. Así, la pionera Ley de Fundaciones de Liechtenstein (1926) reconoce el concepto de "Fundación de Familia" y otorga a ésta capacidad jurídica y de obrar ${ }^{3}$. Posteriormente, la Ley n ${ }^{\circ} 25$ de Fundaciones de Panamá (12 de Junio de 1995), inspirándose en la anterior, otorga personalidad jurídica a las Fundaciones de Interés Privado ${ }^{4}$. De esta forma, ambas leyes dan validez a las instituciones filantrópicas que hayan sido establecidas para la protección del patrimonio y de los miembros de una familia (alimentos, vestido, educación, cobertura sanitaria, etc.). En este sentido, J. Goldsworth sostiene que este tipo de organización es "vehicle for investiment for the benefit of family and other individuals 5 ".

Las fundaciones para actividades de interés privado cuentan con sólidos antecedentes históricos y jurídicos romano-clásicos y fueron recepcionadas por algunos países del Civil law, y, mediante el Trust, por los países del entorno del Common Law ${ }^{6}$. Sin embargo, este tipo de institución no es reconocida por nuestra legislación española actual. Esta última ampara a las fundaciones de interés público para el cumplimiento unilateral e inamovible de fines filantrópicos colectivos sin ánimo de lucro. Así, nuestra C.E de 1978 establece en su artículo 34.1: "Se reconoce el derecho de fundación para fines de interés general, con arreglo a la ley". En su virtud, ha sido promulgada la Ley estatal $^{7}$ 50/ 2002 de 26 de Diciembre, de Fundaciones, que establece en su artículo 2: "Son fundaciones las organizaciones constituidas sin fin de lucro que, por voluntad de sus creadores, tiene afectado de modo duradero su patrimonio a la realización de los fines de interés general". Una vez definida la institución, el artículo 4 de la misma norma consagra la personalidad jurídica de aquélla: "Las fundaciones tendrán personalidad jurídica desde la inscripción de la escritura pública de su constitución en el correspondiente registro de fundaciones". De este modo nuestro legislador distingue dos instituciones diferentes. Por una parte la fundación como institución que persigue fines no lucrativos mediante la voluntad unilateral de un instituyente. Por otra su personificación como ente corporativo. Personificación, que desde un punto de vista histórico jurídico, es el fruto de un largo periodo evolutivo.

En esta dirección, y, como punto de partida, aunque el Derecho Romano conoció ambos tipos de actividades fundacionales sin ánimo de lucro (privadas, en interés del grupo familiar, y públicas, en interés general de la colectividad), nuestro estudio se dirige a analizar el proceso histórico-jurídico que se desarrolló en la civilización romana, que permitió el nacimiento de las fundaciones. Analizaremos, además, su posterior desenvolvimiento como organizaciones o entes jurídicos corporativos autónomos, dotados de las facultades propias de la personalidad jurídica artificial. Instituciones filantrópicas vinculadas al cumplimiento de una voluntad unilateral colectiva y perpetua, sin ánimo de lucro. Fenómeno jurídico que es el pilar maestro histórico jurídico que ha permitido la personificación de ambos tipos de fundaciones.

3 PGR. Arto 109 y 110.

4 Ley $n^{\circ} 25$ de Fundaciones de Interés Privado de Panamá: art ${ }^{\circ}$ : "La inscripción del Acta Fundacional en el Registro Público le otorgará a la fundación personalidad jurídica sin necesidad de ninguna otra autorización legal 0 administrativa".

5 Goldsworth J., "Private Foundations: Law \& Practice", UK., 2011, p. 2.

6 Goldsworth J., loc. cit. n.2, p. 2 y 5 - 20.

7 Las Comunidades autónomas también tienen competencia legislativa en materia de fundaciones. Se aplicará la ley estatal en aquellas CCAA. que no tengan asumida la competencia, o no tengan ley autonómica propia, siempre que la fundación opere exclusivamente en su territorio. Si la fundación desarrolla sus actividades en varias CCAA, o en todo el territorio nacional se aplicará, en todo caso, la legislación del Estado (Ley 50/2002). 


\section{ACTIVIDADES JURÍDICAS FUNDACIONALES PRIVADAS CON FINES PRIVADOS COLECTIVOS Y ACTIVIDADES JURÍDICAS FUNDACIONALES PRIVADAS CON FINES PÚBLICOS DE INTERÉS GENERAL EN EL DERECHO ROMANO CLÁSICO}

Los ciudadanos romanos sintieron frecuentemente la necesidad de transcender al tiempo y perpetuar su memoria en el seno de su colectividad, mediante el desarrollo de actividades filantrópicas perennes en beneficio público. Este fenómeno histórico jurídico que nació del amor que los hombres profesan por la humanidad y, en otras ocasiones, por sus creencias de ultratumba, cuenta con amplios antecedentes en el Derecho griego ${ }^{8}$, que influyeron, al menos, de forma indirecta en la civilización romana. Es por ello que, en numerosas ocasiones, los ciudadanos romanos, movidos por razones privadas de pietas intertemporal, quisieron proteger tanto a los miembros como el nombre de su familia. En esta dirección, se debe situar aquí el parecer acertado de Antonio Fernández de Buján, quien sostiene que ya en los primeros siglos existe una realidad fundacional en Roma9.

De acuerdo, con esta tesis, ya en los primeros siglos de Roma debemos distinguir dos tipos de realidades, o actividades fundacionales. Una realidad fundacional privada dirigida a la protección de grupos determinados de personas o individuos y una realidad fundacional privada dirigida a la consecución de fines públicos colectivos o filantrópicos. A tal fin, los ciudadanos que sintieron esta necesidad, o costumbre (según el parecer de B. Santalucia) ${ }^{10}$ fundacional, podían desprenderse, de forma privada, de todo o parte de su patrimonio y destinarlo de forma unilateral y perpetua a la consecución de beneficios y fines no lucrativos, es decir, de intereses públicos. Del mismo modo, los ciudadanos podían destinar su patrimonio a la protección, sustento y educación intergeneracional de los más allegados y de sus descendientes, incluso a la cobertura y seguridad de terceros próximos. Las fuentes jurídicas clásicas y epigráficas constatan esta doble actividad privada fundacional.

Los mecanismos o medios jurídicos para llevar a cabo los fines filantrópicos fueron las donaciones inter vivos y mortis causa, los legados y los fideicomisos. Mediante éstos, el disponente de la actividad fundacional imponía, para asegurar el cumplimiento de ésta, una carga modal perpetua a los instituidos, destinatarios y patronos del patrimonio fundacional, quienes debían actuar, de acuerdo con la voluntad rectora del instituyente, sin ánimo de lucro, en favor de los beneficiarios. Además, cualquier ciudadano y ciudadana, fundador o fundadora, podían establecer precauciones, castigos, e incluso sanciones económicas a los posibles transgresores de su voluntad filantrópica fundacional.

En el libro XXXI, “De Legatis et Fideicommissis" y en los libros XXX, XXXIII y XXXV del Digesto, que fueron compilados por los juristas de Justiniano, se recogen algunos casos de estas actividades fundacionales privadas que fueron instituidas para fines de protección familiar. También, los juristas resuelven supuestos de actividades fundacionales privadas que fueron instituidas para fines colectivos públicos. Casos que fueron seleccionados y extraídos por los juristas bizantinos de los escritos de los juristas clásicos Scaevola, Paulo y Papiniano:

\footnotetext{
8 Visscher F., s.v. Fondazione (Diritto Greco), en NDI. vol. VII, 1957, pp. 429 - 430.

9 Fernández de Buján A., "Derecho Privado Romano", 8ª ed., lustel, Madrid, 2015, p. 203.

10 Santalucia B., s.v. Fondazione (dir. rom), en ED. vol. 17, 1968, p. 775.
} 
Concretamente, Scaevola nos reporta tres supuestos de estas actividades filantrópicas privadas:

a) Scaevola en libro tertio responsorum:

Lucius Titius testamento ita cavit: "Praediorum meum dari volo libertis libertabusque meis et quos hoc testamento manumisi et Seiae alumnae meae, ita ne de nomine familiae meae exeat, donec ad unum proprietas perveniat". Quaero, an Seia in communione cum libertis habeat portionem an vero sibi partem dimidiam eius praediori vindicare possit. Respondi perspicuam esse testantis voluntatem omnes ad viriles partes vocantis. ${ }^{11}$

Lucio Ticio nombró herederos en el testamento a los libertos de su familia y a su alumna Seya. Además, manumitió a sus esclavos y les legó un predio con la condición de que este patrimonio quedase vinculado permanentemente al nombre de su familia. El testador creó un condominio hereditario - Seia in communio cum libertis -. El testador impuso una carga modal que debían respetar todos los instituidos: la vinculación colectiva en condominio del patrimonio familiar tenía que perdurar en el grupo familiar de sus libertos hasta que la propiedad del predio recayese finalmente en uno solo de aquéllos: donec ad unum proprietas perveniat. Este supuesto es un caso de actividad fundacional privada, pues el testador, al decir de Scaevola, vincula su patrimonio privado de modo colectivo e intergeneracional en beneficio de los miembros de su familia.

b) También Scaevola en libro 18 digestorum:

Codicillis fideicommissa in haec verba dedit: "Libertis libertabusque meis et quos in codicillis manumisi fundum, ubi me humari volui, dari volo, ut qui ab his decesserit, portio eius reliquis adcrescat, ita ut ad novissimum pertineat: post cuius novissimi decessum ad rem publicam Arelatensium pertinere volo. Hoc amplius libertis libertabusque meis habitationes in domo, quamdiu vivent: Pactiae et Trophimae diaetas omnes, quibus uti consuevit: habitet quam domum post mortem eorum ad rem publicam pertinere volo". Quaesitum est, rei publicae fideicommissum utrum ab herede an a libertis datum sit. Respondit secundum ea quae proponerentur posse ita verba accipi, ut eius legatarii, qui novissimus decederet, fidei commissum videatur. Idem quaesiit defunctis quibusdam ex libertis, quibus habitatio relicta erat, an portiones domus, in quibus hi habitaverant, iam ad rem publicam pertineant. Respondit, quoad aliquis eorum vivat, fideicommissum rei publicae non deberi. ${ }^{12}$

En este texto Scaevola reporta un supuesto de actividad privada fundacional. El instituyente utiliza fideicomisos codicilares para disponer de una finca, en la que será enterrado, en favor de sus libertos. Los fideicomisarios beneficiarios reciben en condominio el predio y quedan sujetos al cuidado de la sepultura del fideicomitente. Cuando fallezca el último liberto, la finca pasará a la rem publicam Arelatensium. Aunque

11 D.31.88.6. Scaevola libro tertio responsorum.

12 D.33.2.34. Scaevola libro XVIII digestorum.

Revista Juris Poiesis ano 19, n 19, jan-mai.2016 ISSN 2448-0517 
no se dice en el texto, se puede inferir, que una vez finalizada la voluntad fundacional primigenia, el instituyente quiso que su fundación privada pudiese continuar para seguir cumpliendo con la voluntad fundacional. Es por ello, que el disponente nombró a la rempublicam Arelatensium como fideicomisario sustituto, para que ésta recibiese la propiedad del fundo y, como nueva beneficiaria del patrimonio fundacional vinculado, siguiese dando cumplimiento, de modo perpetuo, al fin establecido por su voluntad unilateral: el cuidado y la protección de la sepultura del fundador.

c) Y, por último, Scaevola en libro 19 digestorum:

Libertis omnibus legavit domum et haec verba adiecit: "Ut in ea habitent liberti, ne de nomine exeat et ut ad unum, qui novissimus exstiterit, perveniat: et eo amplius eisdem libertis meis dari volo fundum sosianum". Quaesitum est, an condicio adposita, ne de nomine exiret, ad sequens quoque legatum pertineret. Respondit pertinere. ${ }^{13}$

El testador dispone, mediante testamento, de un legado por el que atribuye la propiedad de su casa a todos sus libertos. Además, el instituyente ordena, mediante una carga modal, que la propiedad de la casa no pueda salir de su familia. Mediante el legado el testador constituye un condominio hereditario que da soporte patrimonial al desarrollo de una actividad fundacional privada. Esta última es establecida a través de una voluntad unilateral testamentaria que debe ser cumplida y es exigible en los tribunales. Voluntad fundacional que tiene un fin colectivo, pues protege y beneficia a todos los miembros de su la familia.

Por su parte, Paulo también nos reporta varios supuestos que constituyeron instituciones privadas fundacionales, que fueron realizadas para fines colectivos públicos sin ánimo de lucro y que transcendían a la vida del fundador:

a) Paulo en libro tertio regularum sostiene:

Civitatibus legari potest etiam quod ad honorem ornatumque civitatis pertinet: ad ornatum puta quod ad instruendum forum theatrum stadium legatum fuerit: ad honorem puta quod ad munus edendum venationemve ludos scenicos ludos circenses relictum fuerit aut quod ad divisionem singulorum civium vel epulum relictum fuerit. Hoc amplius quod in alimenta infirmae aetatis, puta senioribus vel pueris puellisque, relictum fuerit ad honorem civitatis pertinere respondetur. ${ }^{14}$

Este texto demuestra la existencia de variadas fundaciones privadas sin ánimo de lucro en beneficio de los intereses colectivos públicos, en la Roma clásica del siglo II d. C. Los ciudadanos romanos establecían unilateralmente en sus legados voluntades fundacionales perpetuas (honor y ornato de la ciudad, honorem ornatumque civitatis) que tendrían validez y entrarían en vigor después de sus muertes. A tal fin, según Paulo, los instituyentes designaban como patronos del patrimonio fundacional y como ejecutores de su voluntad a las ciudades. Estas corporaciones cuidarían, gestionarían el patrimonio y

13 D. $35,1,108$. Scaevola libro XIX digestorum.

14 D. 30.122. Paulus libro tertio regularum. 
velarían por el cumplimiento periódico de la voluntad fundacional en beneficio de la colectividad. Ciertamente estas fundaciones de alimentos, educación e instrucción de niños y niñas pobres, construcción y mantenimiento de obras públicas, espectáculos y fiestas regulares, no tenían personalidad jurídica, pero es evidente que los fundadores lograban así la institucionalización jurídica perpetua de sus actividades fundaciones privadas con fines colectivos.

b) Paulo en el libro 14 responsorum:

Seia libertis suis fundum legavit fideique eorum ita commisit: "Fidei autem vestrae, vere et sapide, committo, ne eum fundum vendatis eumque qui ex vobis ultimus decesserit, cum morietur, restituat Symphoro liberto meo et successori et Beryllo et Sapido, quos infra manumisi, quive ex his tunc supervivent". Quaero, cum nec in prima parte testamenti, qua fundum praelegavit, eos substitutit, in secunda tamen adiecerit verbum "qui ultimus decesserit", an pars unius defuncti ad alterum pertineret. Paulus respondit testatricem videri in eo fideicommisso, de quo quaeritur, duos gradus substitutionis fecisse, unum ut is, qui ex duobus prior morietur, alteri restitueret, alterum ut novissimus his restitueret, quos nominatim postea enumeravit. ${ }^{15}$

El fragmento reporta la posibilidad jurídica que asiste a los ciudadanos de establecer un fideicomiso para constituir una actividad fundacional privada. Según Paulo, Seia estableció un fideicomiso mediante el que encomendó a la fidelidad de sus libertos herederos (Beryllo y Sapido) que no vendiesen un fundo. Además, aquélla dispuso que después de su muerte, se restituyese el fundo a otro grupo de esclavos manumitidos, o a cualquiera de ellos que sobreviviesen (Symphoro liberto meo et successori et Beryllo et Sapido, quos infra manumisi, quive ex his tunc supervivent). Según Paulo existieron dos grados de substitución de herederos fideicomisarios con derecho de sucesión en el fundo descrito. El texto del jurista viene a demostrar que los ciudadanos y las ciudadanas recurrían frecuentemente a la constitución de legados y fideicomisos para establecer voluntades unilaterales fundacionales protectoras de su familia y de su patrimonio, al objeto de perpetuar el nombre de aquélla.

Por último, Papiniano también nos informa de la existencia de actividades fundacionales privadas para fines colectivos:

Libertis praedium reliquit ac petit, ne id alienarent utque in familia libertorum retinerent. Si excepto uno ceteri partes suas vendiderint, qui non vendidit ceterorum partes, quibus non dedit alienandi voluntatem, integras petet: eos enim ad fideicommissum videtur invitasse, qui iudicio paruerunt: alioquin per absurdum erit vice mutua petitionem induci, scilicet ut ab altero partem alienatam quis petat, cum partem suam alienando perdiderit. Sed hoc ita procedere potest, si pariter alienaverint: ceterum prout quisque prior alienaverit, partem posterioribus non faciet: qui vero tardius vendidit, ei qui non vendidit in superiorum partibus fecisse partem intellegitur. At si nemo

${ }^{15}$ D.31.87.2. Paulus libro 14 responsorum. 
vendiderit et novissimus sine liberis vita decesserit, fideicommissi petitio non supererit. 16

Papiniano reporta un caso de un testador que estableció un fideicomiso en favor de sus libertos. El disponente pidió a sus libertos que no vendiesen la finca en la que habían sido instituidos y que la retuviesen en la familia mientras viviesen. Según, el jurista, si alguno de los libertos vendió su porción se considera apartado del fideicomiso por desobediencia a la voluntad unilateral del fideicomitente. En consecuencia, el fideicomisario que no vendió puede pedir la porción del fideicomiso vendida. Según sostiene Papiniano, sólo en el supuesto que ninguno de los beneficiarios no hubiese vendido y el último de los libertos hubiese fallecido sin hijos, no subsistirá el derecho de petición del fideicomiso. Aunque el texto no establece el fin de la voluntad del instituyente, sí se puede deducir, de forma indirecta, que nos encontramos ante una actividad fundacional privada cuyo fin fue, probablemente, la protección colectiva intergeneracional del nombre de la familia y de su patrimonio más allá de la vida del instituyente.

\section{ACTIVIDADES FUNDACIONALES ALIMENTARIAS PRIVADAS}

Otra actividad fundacional importante fue constituida y desarrollada por los poderes públicos y los ciudadanos y tuvo por objeto la alimentación, la nutrición, y, en algunos supuestos, la instrucción de niños y niñas pobres, ciudadanos plebeyos, de Roma, sus ciudades y municipios. Así, es seguro que ya en el periodo republicano, los magistados romanos, movidos por el ansia del honor y de la gloria colectiva, recurrieron frecuentemente al reparto de dinero (misilia) y congiarios entre la población plebeya, generalmente los días festivos y las fechas señaladas para la celebración de los espectáculos públicos ${ }^{17}$. Praxis que fue seguida regularmente por los príncipes en el Imperio $^{18}$. Los congiarios consitían en raciones de alimentos (pan, aceite, vino, etc.), que servían para satisfacer las necesidades básicas de subsistencia de los ciudadanos indigentes y de los más necesitados. Este espíritu de liberalidad filantrópica pública, cuenta con viejos antecedentes que se originaron en los territorios y provincias orientales helenísticas. Así, desde la óptica del Derecho griego, si creemos a F. De Visscher, ya en el siglo II a d. C., un tal Eudemo de Mileto, movido por su afán de liberalidad, hizo una cuantiosa donación para la educación y la instrucción permanente (se deben comprender alimentos) de los niños pobres griegos de su ciudad. Las causas que movieron a Eudemio a instituir su voluntad fundacional fueron perseguir el bien común de su pueblo, la obtención de la fama personal y de la gloria perenne ${ }^{19}$.

Posteriormente estas prácticas fundacionales privadas debieron influir también en los ciudadanos ricos de Roma, pues sabemos que algunos años más tarde, ya en tiempos de Nerón, un T. Helvius Basila legó cuatrocientos mil sestercios para la compra de trigo y la alimentación de niños y niñas de la comunidad de Atina ${ }^{20}$. De este modo, T. Helvius

\footnotetext{
16 D. 31.77.27. Papinianus libro octavo responsorum.

17 Juvenal, Sátiras L. 10, 75 - 80.

18 Augusto, Res Gestae Divi Augusti, 15. Suetonio, Augusto, 40 - 42 y 75.

19 De Visscher F., s.v. Fondazione (Diritto Greco), en NDI. vol. VII, 1957, p. 430.

20 C.I.L. 10.556.
} 
constituyó también una actividad fundacional filantrópica privada (alimenta) con fines colectivos.

Y en la misma dirección, Plinio "El Joven" (aproximadamente en el 98 d. C.) asesoró a su amigo Caninio sobre el modo de instituir una fundación (deliberas mecum, quemadmodum pecunia, quam municipibus nostris in epulum obtulisti, post te quoque salva sit) ${ }^{21}$ alimentaria privada permanente (quae in alimenta ingenuorumque) ${ }^{22}$ con fines de utilidad pública (sed oportet privatis utilitatibus publicas, mortalibus aeternas anteferre $)^{23}$. Caninio tenía dudas de cómo asegurar que su patrimonio fuese perpetuamente destinado a convites públicos para sus conciudadanos. Plinio, ante esta honesta consultatio de su amigo, le aconsejó que siguiese los mismos pasos que él dio cuando instituyó su fundación alimentaria en favor de los niños y de las niñas pobres del municipio de Novum Comum. El problema de Caninio era estrictamente jurídico, pues deseaba desprenderse de modo definitivo de parte de su capital fundiario y quería destinarlo a la realización de una actividad fundacional privada invariable que tuviese vida más allá de su muerte. El problema era cómo poder llevarlo a la práctica, desde la óptica del Derecho:

Deliberas mecum quemadmodum pecunia, quam municipibus nostris epulum obtulisti, post te quoque salva sit. Honesta consultatio, non expedita sententia. Numeres rei publicae summam: verendum est ne dilabatur. Des agros: ut publici neglegentur. Equidem nihil commodius invenio, quam quod ipse feci. Nam pro quingentis milibus nummum, quae in alimenta ingenuorum ingenuarumque promiseram, agrum ex meis longe pluris actori publico mancipavi; eundem vectigali imposito recepi, tricena milia annua daturus. Per hoc enim et rei publicae sors in tuto nec reditus incertus, et ager ipse propter id quod vectigal large supercurrit, semper dominum a quo exerceatur inveniet. Nec ignoro me plus aliquanto quam donasse videor erogavisse, cum pulcherrimi agri pretium necessitas vectigalis infregerit. Sed oportet privatis utilitatibus publicas, mortalibus aeternas anteferre, multoque diligentius muneri suo consulere quam facultatibus. Vale. ${ }^{24}$

Plinio, tal vez inspirado por los créditos fundacionales que había ideado Nerva, desarrolló un método ingenioso de simulación de actos jurídicos, que en algunos momentos bordeaba la antijuricidad, no solo de llevar a cabo su propia fundación privada alimentaria, sino también de su perpetuación institucional. A tal fin, le previno que donar su patrimonio a la ciudad - numeres rei publicae summam - podía conllevar el riesgo de que los munícipes no respetasen su voluntad fundacional y dilapidasen su patrimonio verendum est, ne dilabatur -. Por ello, Plinio advierte a su amigo que si donaba sus fundos como propiedad pública al municipio, tal acción podía constituir, a priori, una actitud negligente (Des agros: ut publici neglegentur). En estas circunstancias, Plinio optó por dar nuevos consejos jurídicos a Caninio sobre la manera correcta de proceder. Así, Plinio reporta que lo primero que él hizo fue llegar a un acuerdo de venta con la corporación municipal de Novum Comun. A tal fin, mancipó (venta real) al fisco de la res publica Comensium su finca por un valor ficticio de quinientos mil sestercios. Sin embargo, según

21 Plinio, Epistolae 7.18.
22 Plinio, Epistolae 7.18.
23 Plinio, Epistolae 7.18.
24 Plinio, Epistolae 7.18. 
reporta el texto, el precio de tasación de la hacienda agrícola era muy superior. Además, es obvio que, al ser un negocio fingido, el precio tampoco fue abonado por el actor publicus a Plinio. En definitiva, se trató de una mancipatio simulada, pues, como se deduce de la narración, la mancipatio encubría una donación (Nec ignoro me plus aliquanto quam donasse videor erogavisse, cum pulcherrimi agri pretium necessitas vectigalis infregerit). Esta mancipatio, o compra y venta real ficticia, fue el título que legitimaba la transferencia de la propiedad privada de Plinio a la propiedad pública municipal de la Republica Comensium. Posteriormente, por un acuerdo de Plinio con el actor publicus, la finca se subastó y fue a su vez gravada con el pago de un vectigal que también estaba previamente acordado por ellos. Plinio participó en la subasta y se la adjudicó. Obviamente, la subasta también debió ser un verdadero acto de teatro fraudulento realizado por las partes, tanto por el concedente como por el concesionario. De esta forma, tanto el licitador como el adjudicatario evitaron dolosamente la concurrencia de posibles terceros interesados, que habrían estado legitimados para participar en la subasta pública. De este modo, Plinio se situó en la posición jurídica de possessor tributario perpetuo de un ager vectigalisque, ahora propiedad pública de la Republica Comensium. Este nuevo título le permitió, además, seguir cultivando y explotando libremente el mismo predio. Así, fruto de la adjudicación, y ahora como nuevo concesionario arrendatario (conductor del ager vectigalisque municipal), Plinio se convirtió en deudor y obligado tributario, pues forzosamente tenía que abonar anualmente una renta fiscal, o vectigal, por la cantidad de treinta mil sestercios. Este precio del canon fiscal, al ser simulado de común acuerdo por las partes, fue tasado por debajo del valor real de venta de mercado del predio, y, en consecuencia, fue establecido muy por debajo de su potencial rentabilidad, que era evidentemente muy superior (per hoc enim et rei publicae sors in tuto nec reditus incertus, et ager ipse propter id quod vectigal large supercurrit).

Plinio lograba así la perpetuidad de su voluntad fundacional filantrópica. Por una parte, aquél conseguía que siempre hubiese ciudadanos interesados en seguir con la explotación de la finca como possessores del ager vectigalisque (semper dominum a quo exerceatur inveniet). Es decir, nuevos concesionarios tributarios que, además, continuarían pagando forzosamente el vectigal fundacional a la ciudad. Y por otra, Plinio aseguraba que mediante el pago del vectigal, el municipio de Novum Comun siempre obtendría ingresos tributarios e intereses públicos fundacionales anuales, ya que los treinta mil sestercios (dinero fiscal público) quedaban forzosamente afectados y vinculados perpetuamente a la voluntad unilateral del instituyente fundador. Fin fundacional sin ánimo de lucro, colectivo y de utilidad pública: el mantenimiento y el sustento (alimenta) de los niños y de las niñas libres plebeyos, ciudadanos romanos pobres del municipio de Novum Comum.

Estas fundaciones alimentarias privadas no fueron actividades alisladas. Por el contrario, debieron ser muy numerosas y fueron constituidas, de modo regular, por los ciudadanos y las ciudadanas durante toda la época clásica. De ello da cuenta fidedigna el jurista Paulo, quien sostiene, además, que, mediante legados, los instituyentes pueden constituir fundaciones alimentarias perpetuas, sin ánimo de lucro, en beneficio de los más necesitados, por razón de su edad, (niños, niñas y ancianos). Esta causa fundacional es de interés público ya que, según Paulo, pertenecía al honor de la ciudad:

Civitatibus legari potest etiam quod ad honorem ornatumque civitatis pertinet: ad ornatum puta quod ad instruendum forum theatrum 
stadium legatum fuerit: ad honorem puta quod ad munus edendum venationemve ludos scenicos ludos circenses relictum fuerit aut quod ad divisionem singulorum civium vel epulum relictum fuerit. Hoc amplius quod in alimenta infirmae aetatis, puta senioribus vel pueris puellisque, relictum fuerit ad honorem civitatis pertinere respondetur. ${ }^{25}$

También, en los comienzos del siglo III d. C. Elio Marciano reporta en el Libro XIII de sus Instituciones que:"si quid relictum sit civitatibus, omne valet, sive in distributionem relinquatur sive in opus sive in alimenta vel in eruditionem puerorum sive quid aliud". ${ }^{26}$

Según este jurista clásico son válidos los legados y las donaciones patrimoniales que reciban las ciudades para ser destinados a la alimentación y la educación escolar de niños pobres, así como para cualquier otra finalidad filantrópica de esta naturaleza colectiva. Estas prácticas privadas, que responden al ejercicio del officium pietatis del ciudadano romano, debieron constituir una costumbre muy reiterada en todas las ciudades del Imperio clásico. Y, evidentemente, creemos que se trataron de liberalidades que constituyeron actividades muy consolidadas que generaron auténticas instituciones fundacionales privadas permanentes de utilidad pública: "alimenta, eruditionem puerorum sive aliud".

\section{ACTIVIDADES FUNDACIONALES ALIMENTARIAS PÚBLICAS}

Desde la óptica de la actividad pública, fue el Estado romano, como persona jurídica, y en su nombre el emperador con quien se confunde, quienes instituyeron diferentes actividades fundacionales filantrópicas colectivas de sustento e instrucción en beneficio de terceros. En esta dirección, aunque A.N. Sherwin - White ${ }^{27}$ cree que fue Domiciano quien creó las fundaciones alimentarias, sin embargo, según reporta el historiador y político del siglo IV d. C. Ps-Aurelius Victor, en sus escritos sobre la Roma imperial, fue Nerva quien tuvo el honor de ser el primero que diseño los alimenta como institución asistencial pública, con cargo a las arcas públicas del Estado: "puellas puerosque natos parentibus egestosis sumptu publico per Italiae oppida ali iusssit" 28 . Por ello, tal vez, también es acertada la opinión de R. Ducan Jones, quien sostiene que los comentarios que hace Plinio en el capítulo 28 de su Panegírico a Trajano sobre los alimenta en Italia no son concluyentes para poder atribuir a Domiciano la paternidad de las fundaciones alimentarias. Se trataría, según su opinión de "alimenta need be no more than the accustomed payments to the plebs". ${ }^{29}$

Con esta afirmación, R Ducan Jones parece referirse a los congiarios que enraizan con viejos precedentes republicanos, pues eran realizados frecuentemente al libre albedrío de los magistrados mediante liberalidades consuetudinarias. Subsidios asistenciales que se siguieron practicando posteriormente por los príncipes en el Imperio. Así, según nos

25 D. 30.122. Paulus libro tertio regularum.

26 D. 30.117, Marcianus Libro XIII Institutionum.

27 Sherwin - White A.N., "The letters of Pliny", Oxford, 1985 p. 104, 422 ss.

28 Ps-Aurelius Victor, De Caesaribus 12.4.

29 Ducan - Jones, R. "The Economy of the Roman Empire", Cambridge 1984, reimpresión 1982, p. 291. 
informa Suetonio, Augusto distribuyó numerosos congiarios entre la población ${ }^{30}$. Esta subsidiación de alimentos a la plebe fue seguida posteriormente por los príncipes de la estirpe de la dinastía Julio - Claudia. Sin embargo, nos parece evidente que el reparto ocasional de vino, aceite, pan, dinero, mediante congiarios, aunque constituyó una auténtica actividad filantrópica de liberalidad de los emperadores, no respondió a las características jurídicas de una actividad fundacional alimentaria permanente. En este sentido W. H. Byrnes cree que esta política de pan y circo (Juvenal, Sátiras L.10, 75 - 80) y este tipo de caridad romana buscaban seducir a las masas y responderían a la necesidad de búsqueda de la gloria y de la inmortalidad por los emperadores romanos ${ }^{31}$.

Con todo, es seguro que algunos años después del mandato del emperador Nerva, como es atestiguado por Plinio el Joven ${ }^{32}$, Dion Casio ${ }^{33}$ (en su Historia de Roma) y por numerosas fuentes epigráficas, tanto Trajano como Adriano instituyeron numerosas actividades fundacionales alimentarias públicas que tuvieron por fines el mantenimiento y el sustento de los niños y de las niñas pobres de numerosos municipios y ciudades de la península itálica.

Así, el emperador Trajano creó varios programas fundacionales públicos ambiciosos, mediante el recurso a mutuos fiscales hipotecarios que fueron garantizados por los mutuarios con avales reales (praedes). Los préstamos prendiarios fueron convenidos para el mantenimiento perpetuo de niños pobres. De esta forma, la actividad y la voluntad unilateral establecidas por el Príncipe (cultivo y prestación de alimenta) fueron ligadas a la propiedad de los predios como patrimonio fundacional. Así, tal como reza en una Tabula ex Ligures Baebiani (100 d. C.):

[Imp. Caes.] Nerua Traiano Aug. G[ermanic]o IIII| [Q.] Articuleio Paeto [cos. | _ — — — optim]i maximiq(ue) principis obligarunt prae[dia - - - ]pto Ligures Baebiani [_- _ _ _ _ - _ $]$ t ex indulgentia eius pueri pu<〈a>> ellaeq(ue) a[limenta a]ccipiant. $\|^{34}$

Y en una Tabula Obligationis Praediorum Veleiatae (109 - 112 d. C.): Obligatio praediorum ob HS deciens quadraginta quattuor milia ut ex indulgentia optimi maximique principis Imp(eratoris) Caes(aris) Nervae /Traiani Aug(usti) Germanici Dacici pueri puellaeque alimenta accipiant legitimi n(umero) CCXLV in singulos HS XVI n(ummum) f(iunt) HS XLVII(milia) XL n(ummum) legitimae n(umero) XXXIV sing(ulae) HS XII n(ummum) f(iunt) HS IV[(milia)] DCCCXCVI spurius HS CXLIV spuria HS CXX / Summa HS LII(milia) CC quae fit usura $\mid$ (quincunx) sortis supra scribtae(!). ${ }^{35}$

En ambos casos, el Fisco romano, en el nombre y por orden de Trajano, constituyó un mutuo fiscal, o préstamo personal (un millón cuarenta y cuatro mil sestercios para Veleia, HS deciens quadraginta quattuor milia) con garantía real hipotecaria al cinco por ciento de interés (tasa no especificada en la Tabula Baebiani). Los beneficiarios de los

\footnotetext{
30 Augusto, Res Gestae Divi Augusti, 15. Suetonio, Augusto, 40 - 42 y 75.

31 Byrnes W.H., "Ancient Roman Munificience: The Development of the Practice and Law Charity", en vol. 57 Rutgers Law Review 1043 (2005) p. 1058, available at http://ssrn.com/abstract=2314731.

32 Plinio. Paneg. Cp. 28: "Paullo minus, Patres Conscripti, quinque millia ingenuorum fuerunt, quae liberalitas principis nostri conquisivit, invenit, adscivit".

33 Dion Casio, 68.5.4.

34 C.I.L. IX.1455.

35 C.I.L. XI.1147.
} 
préstamos personales debían garantizar estos últimos mediante prendas hipotecarias constituidas sobre el valor de sus predios y fincas (praedes). La explotación de las fincas agrarias debía generar al menos una usura del 5\%. Esta última constituía una tasa de interés fundacional, ya que no sólo tenía que ser forzosamente abonada mediante pago en antricresis, sino que también tenía que ser forzosamente destinada a dar cumplimiento de las actividades fundacionales alimentarias tanto en favor de los niños y las niñas pobres del municipio de Veleia como del municipio de los Ligures Baebiani. De esta forma, el Estado romano fomentaba el cultivo de las explotaciones y predios agrarios de estas poblaciones, y, además, estos bienes raíces agrarios servían como garantía real al préstamo fiscal público.

De esta forma, el Estado romano institucionalizó, mediante la concesión de créditos financieros públicos blandos, vinculados al pago de intereses en anticresis, una actividad de liberalidad - ex indulgentia - fundacional, de carácter filantrópica - pueri puellaeque alimenta accipiant -, sin límite temporal.

Además, es muy posible que el Estado, concretamente el Fiscus Cesaris, se reservase el derecho de recuperar los préstamos fundacionales otorgados, siempre que los mutuarios fiscales no cumpliesen el fin fundacional (lex commisoria) establecido. Estos últimos estaban sujetos, tal vez, no a la ejecución de una prenda hipotecaria privada, sino a la ejecución tributaria de los predios obligados - obligatio praediorum - mediante las subastas fiscales que surgían de las leges praedatoriae. Sin embargo, si el Tesoro llevaba a cabo adjudicaciones de predios pignoraticios, su actividad fundacional se retroalimentaba con nuevos fondos financieros, pues obtenía dinero de la venta de las subastas. De este modo, el Estado romano creaba una fundación con un sistema autónomo de funcionamiento, pues su actividad no estaba condicionada por el sufrimiento de posibles colapsos financieros anuales del Tesoro. A la par, el Fiscus Cesaris podía sustituir a los viejos deudores ejecutados por nuevos deudores prestatarios que estuviesen interesados en participar en la fundación alimentaria. Nuevos concesionarios a los que se les exigiría por los funcionarios imperiales un nuevo compromiso de obligar a sus predios mediante pignus conventum con pacto añadido de pago de intereses en anticresis (frutos para alimentos). Pacto que permite que los frutos sean imputables tanto al pago del capital del nuevo préstamo fundacional como al pago de sus intereses anuales moderados en concepto de alimenta. Nuevos mutuos que permitirían seguir cumpliendo con los fines de nutrición y sustento instituidos por el Emperador. Además, es posible también que en los supuestos de obtención de remanentes excesivos, el Tesoro romano continuase ampliando y creando nuevas fundaciones en otras ciudades y municipios con la concesión de nuevos créditos pignoraticios. En último término, el Tesoro consideraba a estos recursos financieros (que son obtenidos del patrimonio ejecutado, del valor de los frutos adquiridos, y del dinero público recaudado en las subastas fiscales) como recursos tributarios fundacionales públicos afectados permanentemente al cumplimiento del honor del Estado y de sus entes territoriales municipales, mediante la prestación de alimentos ${ }^{36}$.

En consecuencia, ante situaciones de insolvencia y quiebra de los dueños de las fincas, fue muy probable que el Tesoro no pretendiese la devolución de los préstamos para que volviesen de forma definitiva a su arca imperial. Esto hubiese sido ir contra su propia actividad y voluntad fundacionales. Al contrario, el sistema descrito, es decir, la recuperación de los predios y sus cosechas por impago de intereses, serviría para seguir fortaleciendo el patrimonio y el dinero de la institución fundacional alimentaria pública

${ }^{36}$ D. 30.122. Paulus libro tertio regularum. 
en el tiempo, ya que esta nace y se instituye, desde sus inicios, con vocación de perpetuidad. Así, según sostiene E.T. Salmon, la originalidad de Nerva, seguida posteriormente de Trajano, consistió precisamente "en combinar el mantenimiento de los niños con la financiación de agricultores y traer este esquema bajo el control del Estado"37. Sin embargo, esta originalidad que atribuye ET. Salmon al emperador Nerva, debe ser puntualizada, pues es evidente la influencia del Derecho griego en este sistema fundacional imperial. En este sentido, si creemos a F. de Visscher, ya en Grecia fue común la utilización de préstamos para fines perpetuos beneficiosos para la colectividad. El capital sólo sería devuelto en caso de que cesase el fin fundacional. A tal fin, según F. de Visscher, "spesso la fondazione prende pure la forma di una costituzione di rendita garantita da ipoteca sui beni forniti dal donatore ${ }^{38} "$. De acuerdo con esta información, creemos que la utilización por Nerva y, posteriormente, por Trajano, del pignus con pacto de anticresis, como instrumento jurídico válido para instituir las fundaciones públicas de alimenta, denota y delata claramente su origen griego, al menos, helenístico y oriental.

A pesar de esta evidente influencia, creemos que los programas financieros imperiales de alimentos constituyeron ambiciosas actividades fundacionales públicas genuinas del Estado romano, pues en estas últimas se constatan los elementos jurídicos típicos que las configuran: a) la separación de un patrimonio o dinero propiedad del instituyente, b) su entrega, por el disponente, en concepto de crédito pignoraticio y su vinculación permanete a una voluntad unilateral inamovible: el destino de los intereses al cumplimiento de una voluntad fundacional de liberalidad pública colectiva: la alimentación perpetua de niños y niñas pobres (aproximadamente 5000 niños ya fueron previstos por Trajano: "Paullo minus, Patres Conscripti, quinque millia ingenuorum fuerunt, quae liberalitas principis nostri conquisivit, invenit, adscivit" 39 , 300 beneficiarios del municipio y comarca de Veleia) ${ }^{40}$ c) el nombramiento tácito de patronos o vigilantes protectores de la voluntad fundacional y ejecutores de su estricto cumplimiento: decuriones y duoviri de los municipios de Veleia y del municipio del Samnium de los Ligures Baebiani. Los magistrados municipales recibirían, en nombre y bajo la vigilancia y contabilidad de los quaestores alimentari locales y de los curatores rei alimentariae de la provincia ${ }^{41}$, los alimentos generados por las cosechas de los predios, en concepto de pago y liquidación del interés devengado por el vencimiento de los préstamos fundacionales (pacto de anticresis). Además, los funcionarios y magistrados asignarían individualizadamente los pagos fundacionales en alimentos a los niños y niñas inscritos en la actividad fundacional ${ }^{42}$. También es posible que aquéllos estuviesen facultados para conceder nuevos créditos fundacionales de dinero público en anticresis, dinero recaudado bien por amortizaciones y cancelaciones totales de las deudas hipotecarias de los beneficiarios, bien por ejecución mediante subasta fiscal ex leges praediatoriae del patrimonio fundiario de los deudores prendarios insolventes.

\footnotetext{
37 Salmon E.T. "A History of the Roman World: From 30 B.C. to AD. 138”, 1944, reprinted 2004, London, p. 270.

38 De Visscher F., s.v. Fondazione (Diritto Greco)... cit., p. 430.

39 Plinio. Paneg. Cp. 28: "Paullo minus, Patres Conscripti, quinque millia ingenuorum fuerunt, quae liberalitas principis nostri conquisivit, invenit, adscivit".

40 Papa. G., "Note sulla tabula alimentaria di Veleia", en Labeo, vol. 1 (1994), p. 61

41 Así lo cree Bennet J., "Trajan: Optimus Princeps", $1^{\text {a }}$ edición 1997, reimpresión 2005, London - New York, 2005 p.

82: "Once the quota had been filled, a sum equivalent to twenty times the amount of the benefit needed was given by the treasury to the community, and parcelled out among local landowners by the local quaestores alimentum, supervised by regional senatorial curatores rei alimentariae".

42 En este sentido, Papa. G., cit. p. 61.
} 
Estas características, que son constatadas por las Tablas de Veleia y de Ligures Baebiani, describen los rasgos distintivos que nutren a la naturaleza jurídica clásica de la actividad institucional fundacional pública del Estado imperial. Sin embargo, algunos historiadores han puesto objeciones a que los programas de alimentos imperiales puedan ser considerados fundaciones de utilidad pública en beneficio de los niños pobres. Así, Gregg E. Gadner cree que en el mundo greco - romano la población "were identified as either citizens or no citizen (...) the poor as a distinct social entity was invisible"43. Una objeción, que para nosotros, tal vez es anacrónica, puesto que en el Mundo Antiguo rige el principio de personalidad, por el cual cada individuo tiene un status diferente frente al ordenamiento jurídico de su ciudad ${ }^{44}$. Es por ello, que los alimenta fueron destinados a niños y niñas ciudadanos romanos plebeyos pobres. Sólo estos últimos, como nacionales romanos (status civitatis), podían tener derechos y, en consecuencia, ser beneficiarios del dinero fiscal público que financiaba los créditos de los que surgían los intereses en anticresis que daban soporte patrimonial estable a las fundaciones de alimentos.

Por otra parte, desde una óptica demográfica, R. Ducan - Jones ${ }^{45}$ y T.S. Miller ${ }^{46}$, objetan que los programas fundacionales de alimentos imperiales (calificados, incluso, por J. Benett ${ }^{47}$, como "public alimentary sistem") constituían subsidios que tenían como finalidad el fomento de la natalidad, el crecimiento de las ciudades y el sustento de nuevos ciudadanos romanos (varones itálicos) para sostener los ejércitos imperiales. Sin embargo, estimamos que estos fines constituyeron claros objetivos de utilidad pública fundacional para el Estado romano y un honor público de interés general para las ciudades y los municipios de Italia, y, posteriormente, de las provincias del Imperio ${ }^{48}$. Así, aunque, Greff Woolf ha sostenido que los alimenta no fueron diseñados como fundación para aliviar la pobreza ${ }^{49}$, creo que ciertamente, las fundaciones alimentarias del Estado permitieron no sólo nutrir, sino también vestir, y, posiblemente, educar a niños y niñas, ciudadanos plebeyos pobres ${ }^{50}$ de Italia y de las provincias durante varios siglos. Actividad tal vez iniciada por Nerva, quien Tutela Italiae ${ }^{51}$. Este Emperador protegió no sólo a las madres y las viudas, sino también a la infancia pobre. Además estableció un fondo de sesenta millones de sertercios, que fue destinado a la compra de fundos y a su explotación para la alimentación de niños pobres de Italia ${ }^{52}$. Desde finales del siglo I d. C., los beneficiarios de alimenta fueron ciudadanos. Estos últimos eran huérfanos y niños expósitos pobres que estarían situados bajo tutela legítima y dativa. Y, probablemente también, serían beneficiarios de las fundaciones los niños y las niñas, ciudadanos pobres, alieni iuris, bajo patria potestas de un paterfamilias plebeyo sin recursos económicos.

${ }^{43}$ Gadner G. E., "The Origins of Organizated Charity in Rabbinic Judaims", Cambridge University Press, New York, 2015, p. 10.

44 Volterra E., "Instituciones de Derecho Privado Romano", trad. J. daza, Madrid, 1986, p. 78.

${ }^{45}$ Ducan - Jones, R. cit. p. 291.

${ }^{46}$ Miller S. T., "The Orphans of Byzantium: Child Welfare in the Christian Empire", ed. The Catholic University of America Press, Washington D.C., 2003, pp. 31 - 32.

47 Bennet J., cit. p. 82.

48 D. 30.122. Paulus libro tertio regularum.

49 Woolf G., "Food, Poverty and Patronage: The Significance of the Epigrahy of the Roman Alimentary schemes in Early Imperial Italy", en Papers of the British School at Rome 58 (1990), pp. 197 - 228.

50C.I.L. 5262: VIVUS DEDIT IN ALIMENTA PUERORUM ET PUELLARUM PLEBIS URBANAE HS D. D. 30.117 , Marcianus Libro XIII Institutionum: "Si quid relictum sit civitatibus, omne valet, sive in distributionem relinquatur sive in opus sive in alimenta vel in eruditionem puerorum sive quid aliud".

${ }^{51}$ RIC2. Merlin A. "Le grand bronze de Nerva, Tutelae Italiae", en Revue Numismatique, vol. 10, 1906, pp. 298 -301.

52 Grainger J.D. "Nerva and the roman succesión crisis of AD. 96 - 99", ed. Routledge, 2003, London - New York, p. 57. 
Paterfamilias que velaría, además, por el cuidado, la nutrición y la educación de sus hijos e hijas en el seno de su propia familia.

No cabe duda que este espíritu de liberalidad fundacional se expandió por toda Italia y dejó una huella profunda en la sociedad romana y en su Derecho clásico. Los instrumentos jurídicos de este último dieron forma y soporte jurídico a las fundaciones alimentarias públicas de Trajano y de sus sucesores, y, además, sirvió de antecedente jurídico fiel para el posterior desarrollo de los programas de beneficiencia, mediante alimenta, que fueron llevados a cabo por las fundaciones de caridad cristianas en el Bajo Imperio.

Además, se debe poner de relieve que el Estado Romano, fruto del desarrollo de su actividad pública fundacional y del cumplimiento de sus fines de nutrición y educación, ofrecía no sólo la posibilidad futura de contraer un matrimonio legítimo a las niñas, sino también la posibilidad de integrar a los niños en las legiones profesionales. A diferencia, de los orfanatos cristianos del Bajo Imperio, que educaban, pero no preveían ni garantizaban ningún medio futuro de vida, los alimenta sí abrían una expectativa futura sólida de obtener un medio de vida a todos sus beneficiarios. A las niñas, la posibilidad de integrarse como uxores en una familia romana y a los niños la posibilidad de emanciparse, comenzar y desarrollar una vida profesional de éxito en el ejército profesional, así como la posibilidad de promocionar en los escalafones de la carrera militar. En consecuencia, también se daba oportunidad al azar de abrir las puertas del cursus honorum de los beneficiarios, es decir, el derecho de estos últimos de poder presentar, posteriormente, sus candidaturas a los honores de las magistraturas públicas en la vida civil. Es por ello, que esta concepción de los alimenta no es un obstáculo para que puedan ser concebidos, desde la óptica del Derecho clásico, como una institución fundacional de utilidad pública permanente. Precisamente estos fines de interés general para el Estado y sus ciudadanos reafirmaron la naturaleza jurídica primigenia: la nutrición de la infancia nacional romana pobre. Es evidente, que los alimenta generaron una expectativa de vida futura a sus beneficiarios. Pero esta posibilidad fue una consecuencia posterior del desarrollo de la actividad fundacional previa que desarrollaba el Estado romano. Aunque aquella expectativa de vida posterior no era propiamente el fin primigenio de la actividad fundacional, que consistía en el sustento de niños y niñas pobres, de no haber sido por la labor de estas fundaciones públicas de los emperadores (ut ex indulgentia optimi maximique principis) ${ }^{53}$ muchos de aquellos niños y niñas, probablemente, tampoco habrían vivido por falta de nutrición y sustento. También, desde una óptica privada, como analizamos en el apartado anterior, los ciudadanos instituyeron fundaciones privadas filantrópicas de sustento, alimentación, educación y enseñanza de los niños. Plinio estableció una fundación alimentaria en favor de los niños pobres de Novum Comun y, además, aconsejó a su amigo Caninio que siguiese sus mismos pasos ${ }^{54}$. Incluso, en la epigrafía funeraria de Plinio consta el espíritu jurídico fundacional de sus alimenta: VIVUS DEDIT IN ALIMENTA PUERORUM ET PUELLARUM PLEBIS URBANAE HS $D^{55}$ (= 500.000). Actividades fundacionales privadas que, todavía a comienzos del siglo III d. C., debieron ser muy profusas y debieron estar bastante extendidas por los municipios y las ciudades del Imperio ${ }^{56}$.

${ }^{53}$ CIL.XI, n.1147 EX TABULA OBLIGATIONIS PRAEDIORUM VELEIATE. C.I.L. IX.1455 EX TABULA LIGURUM BAEBIANORUM: "ex indulgentia eius pueri pu<<a>>ellaeq(ue) a[limenta a]ccipiant".

${ }^{5}$ Plinio, Epistolae, 7.18.

55 C.I.L. 5262.

${ }^{56}$ D. 30.117 , Marcianus libro XIII institutionum. 
Por todo ello, desde un punto de vista jurídico, creemos que los alimenta constituyeron fundaciones privadas y fundaciones públicas institucionales permanentes clásicas, que aunque carecieron de personalidad jurídica propia, sin embargo, fueron protegidas y desarrolladas por el propio Estado y sus corporaciones. Estas últimas también estaban dotadas de personalidad a exemplum rei publicae. Patrón jurídico que las permitía cumplir y mantener fines perpetuos colectivos de utilidad pública. En este sentido, A. Berger sostiene que "pueri alimentarii (puera alimentaria) are indigente children who received alimenta from either imperial or private foundations (arca alimentaria, pecuniae alimentaria). The supervisions of all such organizations in Italy and in the provinces was assigned to special procuratores (quaestores, praefecti) alimentorum $^{57}$ ". Del mismo modo, como sostiene Paulo ${ }^{58}$, los ciudadanos aprovecharon la personalidad y la perpetuidad pública de los entes corporativos municipales para el desarrollo de sus actividades fundacionales privadas. Por ello, como reporta J.L. Murga Gener en 1965, los caminos que se abrieron ya en el Derecho imperial con las fundaciones alimentarias constituyeron "como los primeros balbuceos en la existencia de la persona jurídica concebida como ficción, como un fin o destino de los bienes, en este caso el de proporcionar alimentos periódicos a niños generalmente. ${ }^{59}$

\section{LA PERSONALIDAD JURÍDICA HABERE CORPUS AD EXEMPLUM REIPUBLICAE, COMO MEDIO JURÍDICO VEHICULAR DE LAS ACTIVIDADES FUNDACIONALES EN LA ÉPOCA CLÁSICA}

Como punto de partida, es posible sostener que ni en la etapa republicana ni en la etapa clásica, las fundaciones fueron concebidas por los juristas romanos como patrimonios dotados de personalidad jurídica artificial. La jurisprudencia clásica no reporta ninguna información de la que se pueda concluir su existencia. Los patrimonios que el fundador destina a una finalidad colectiva perpetua no son concebidos como corpora personificados, es decir, como entes patrimoniales legales independientes que tuviesen la titularidad de una serie de facultades, derechos y obligaciones similares a los que los ciudadanos romanos gozan con plenitud fruto de su status civitatis, es decir, como sujetos de derecho optimo iure. Con todo, de la misma forma que existieron sociedades mercantiles sin personalidad jurídica en la República y en el Imperio, de la misma forma podemos sostener que sí existieron fundaciones jurídicas públicas y privadas que, aunque operaron sin personalidad jurídica propia, desarrollaron su vida institucional mediante la protección de la personalidad jurídica del Estado o de otros entes territoriales. Esta circunstancia fue posibilitada por la creación genuina romana de Derecho público de la institución jurídica de corpora y de universitates personarum. Molde jurídico concedido por el poder público, del que se beneficiaron los entes territoriales, municipios y colonias romanos que se constituyeron como espejos del Estado (ad exemplum Reipublicae) ${ }^{60}$. En

\footnotetext{
57 Berger A. voz: "Alimentarius", en Encyclopedic Dictionary of Roman Law, vol. 43, n.2, $1^{\text {a }}$ ed. 1882, reimpresión 2008, New Jersey, p. 360. También, Bennet J., "Trajan: Optimus Princeps", $1^{a}$ edición 1997, reimpresión 2005, London New York, 2005 p. 82

58 D. 30.122. Paulus libro tertio regularum.

59 Murga Gener J.L., "El Testamento en favor de Jesucristo y de los Santos en el Derecho Romano Postclásico y Justiniano", AHDE. n. 35 (1965) p. 385.

60 D. 3.4.1.1. Gaius libro tertio ad edictum provinciale: "Neque societas neque collegium neque huiusmodi corpus passim omnibus habere conceditur: nam et legibus et senatus consultis et principalibus constitutionibus ea res
} 
efecto los entes municipales fueron dotados de res communes, arcam communem sive syndicum $^{61}$. Este patrón jurídico corporativo permitió a los disponentes integrar sus voluntades, patrimonios y actividades fundacionales (privadas y públicas) perpetuas y sin ánimo de lucro en el seno de todas aquéllas. De esta forma indirecta, el Derecho público romano había posibilitado que cualquier disponente pudiese integrar su voluntad fundacional privada en un ente territorial corporativo independiente autónomo, y, en consecuencia, separado de sus miembros, bien sea en el Estado (Populus Romanus) bien en cualquier otro ente territorial municipal de base corporativa creado ad exemplum Reipublicae. Mediante todos ellos, el disponente podía también dar cumplimiento a su voluntad fundacional, pues podía nombrar a estos como destinatarios del patrimonio fundacional para lograr la perpetuación intertemporal de los fines colectivos y filantrópicos por él establecidos.

En este marco jurídico, es evidente que, ni en la República ni en la época clásica, el patrimonio fundacional privado, del que se desprende el disponente, no está per se personificado. No es un ente o corpora rerum con personalidad jurídica artificial ${ }^{62}$. Es cierto, como sostiene G. Impallomeni, que "durante tutto il diritto clasico non sembra si sia riconosciuta la soggettività a nessum patrimonio autonomo"63. Sin embargo, como admite Paulo ${ }^{64}$, un patrimonio de una actividad fundacional (pública o privada) puede enraizar, vivir, desarrollarse y cumplir sus funciones en simbiosis y bajo la protección del Estado o de una corporación jurídica colectiva territorial personificada ad exemplum Reipublicae. Así bajo la capa y la tutela de un ente corporativo independiente, o corporación personificada por el Derecho público, que goza del privilegio de la imputación como titular de derechos y obligaciones, el patrimonio fundacional puede encontrar pilares que le permitan institucionalizarse y perpetuarse para el logro de sus fines públicos colectivos perpetuos sin ánimo de lucro. De este modo, en época clásica, el patrimonio que era vinculado a una corporación mediante una voluntad fundacional se impregnaba y se visualizaba por los terceros - ciudadanos, en la praxis, como una fundación investida de los ropajes y de la seguridad jurídica de las corporaciones de la re publica. Las corporaciones jurídicas territoriales municipales de la re publica fueron, en numerosas ocasiones, los entes personificados destinatarios del patrimonio que sirvieron de depósitos receptores y de medios o vehículos jurídicos para la institucionalización perpetua de numerosas voluntades fundacionales privadas sin ánimo de lucro. Pues, en último término, aquéllas, guiadas por el cumplimiento del honor y el ornato ${ }^{65}$, vigilaban y protegían los bienes del disponente fundador, para que éstos fuesen destinados al cumplimiento colectivo e inamovible de sus fines ${ }^{66}$. En este sentido, también, el jurista

coercetur. Paucis admodum in causis concessa sunt huiusmodi corpora: ut ecce vectigalium publicorum sociis permissum est corpus habere vel aurifodinarum vel argentifodinarum et salinarum. Item collegia Romae certa sunt, quorum corpus senatus consultis atque constitutionibus principalibus confirmatum est, veluti pistorum et quorundam aliorum, et naviculariorum, qui et in provinciis sunt".

61 D. 4.1.1. Gaius libro tertio ad edictum provinciale: "Quibus autem permissum est corpus habere collegii societatis sive cuiusque alterius eorum nomine, proprium est ad exemplum rei publicae habere res communes, arcam communem et actorem sive syndicum, per quem tamquam in re publica, quod communiter agi fierique oporteat, agatur fiat".

62 Santalucia B. cit. p. 775.

63 Impallomeni G., voz. "Persona Giuridica", en NDI., vol. 12, 1957, p. 1031.

64 D. 30.122. Paulus libro tertio regularum.

65 D. 30.122. Paulus libro tertio regularum: "quod ad honorem ornatumque civitatis pertinet".

66 Plinio, Epistolae. 7.18. Santalucia B. cit. p. 775: "Il criterio maggiormente seguito fu quello di lasciare per mezzo di legati o donazioni, dei beni ad una collettività per sua natura durevole (collegia e sopratutto municipia) assoggetando la stessa all'incombenza di destinare le rendite alle finalità volute del disponente". 
Elio Marciano es concluyente: "Si quid relictum sit civitatibus, omne valet, sive in distributionem relinquatur sive in opus sive in alimenta vel in eruditionem puerorum sive quid aliud"67.

Esta fue la solución aceptada como válida, aunque no siempre fiel como advirtió Plinio el Joven ${ }^{68}$, por la jurisprudencia como método de institucionalizar las fundaciones en el periodo clásico. La frecuencia de recurrir a este medio indirecto para perpetuar la voluntad del instituyente motivó que las fundaciones de la época clásica fuesen designadas por Le Bras ${ }^{69}$, F. de Visscher ${ }^{70}$ y J. Gaudemet ${ }^{71}$ como "fundaciones indirectas" y como "fundaciones "en sentido lato". Incluso, según sostiene R. Feenstra ${ }^{72}$, son "fundaciones impropias" por su falta de personalidad jurídica. Nosotros estimamos que son propiamente fundaciones jurídicas, aunque sin organización corporativa propia (uncorporated foundation). Con todo, la utilización de las corporaciones por los fundadores sirvió tanto para intentar dar un soporte institucional sólido de Derecho público $^{73}$ a sus voluntades unilaterales filantrópicas, como para intentar asegurar que sus patrimonios fuesen protegidos, administrados y destinados regularmente al cumplimiento de los fines colectivos perpetuos sin ánimo de lucro.

\section{ACTIVIDADES FUNDACIONALES PRIVADAS PIAE CAUSAE E INSTITUCIONES FILANTRÓPICAS PÚBLICAS FUNDACIONALES EN EL IMPERIO ROMANO POSTCLÁSICO}

El reconocimiento oficial del Cristianismo como religión aceptada por el Estado en año 313 d. C. (Edicto de Tolerancia) produjo el inicio de una involución no solo de las ideas y de los valores de la filosofía clásica sino también de la vida de los hombres. A pesar de las objeciones de Juliano el Apóstata, quien trató de resturar el culto a los dioses clásicos $^{74}$, el Cristianismo va a ir penetrando con fuerza e intensidad en las propias entrañas administrativas y burocráticas imperiales, hasta convertirse en la nueva y única religión oficial del Estado ${ }^{75}$. Es posible que el Dominado imperial, inaugurado por Diocleciano y Maximiano, se convirtiese, progresivamente, a partir de Constantino, en un nuevo Estado con ropajes cristianos ${ }^{76}$. Proceso que culmina con Teodosio quien transforma al Estado en una nueva autocracia teocrática cristiana ${ }^{77}$.

Esta nueva concepción teológica e imperialista del Estado tendrá consecuencias directas en el fundamento y las causas que mueven a las actividades fundacionales del Derecho Romano del Bajo Imperio y del Derecho romano bizantino de Justiniano. Así, los viejos principios generales jurídicos y filosóficos que actuaban como informadores de

\footnotetext{
67 D. 30.117, Marcianus libro XIII institutionum.

68 Plinio, Epistolae 7.18.

69 Le Bras, "Les fondations privées du Haut Empire", en Studi in onore di S. Riccobono, vol. 3, Palermo, 1936, p. 24.

70 De Visscher F., "Les fondations privées en droit romain classique", en RIDA, vol. II, 1955, p. 286.

71 Gaudemet J., "Les fondations en Occident au Bass Empire", en RIDA, 1955, vol. 2, p. 286.

72 Feenstra R., "The Development of the Concept Foundation in Continental Law", 1971. Acta Juridica, p.124.

73 Impallomeni G., voz. "Persona Giuridica", en NDI., vol. 12, 1957, p. 1029 sostiene que "originariamente le persone giuridiche sono regolate in prevalenza dal diritto publblico, nel cui ambito esse operano".

74 Bowersock G. "Recapturing the Past in Late Antiquity", en MedAnt. vol 4 n.1. 2001, p. 5.

75 CJ.1.1. 1. Gratianus, Valentinianus, et Theodosius (380 d. C.).

76 Bowersock G. "Recapturing the Past...", cit. p. 3: "When the emperor Constantine converted to Christianity and transformed the former Roman Empire into a Christian state (...)".

77 CJ.1.1.1. - 2. Gratianus, Valentinianus, et Theodosius (380 d. C.).
} 
la iustitia clásica y del Estoicismo, son empapados por los nuevos valores que surgen de la inspiración cristiana ${ }^{78}$. El officium pietatis estoico, la equitas y la humanitas, que guían a la iustitia del ciudadano romano, son sustituidos progresivamente por nuevos valores cristianos y divinos, universales: benignitas, caritas y pietas. La liberalitas del ciudadano romano clásico es sustituida por la filosofía de la caridad (caritas) misericordiosa del nuevo ciudadano romano cristiano posclásico. El espíritu fundacional permanece en ambos hombres. Sin embargo, cambian los valores y los fines filantrópicos. La utilidad pública del Estado, el bien de la colectividad, el interés general y la gloria del instituyente, que permanecerá perpetuamente ligada a sus conciudadanos, son sustituidas progresivamente por la caridad, la compasión y la piedad misericordiosa en beneficio de los más necesitados. No sólo ciudadanos romanos, cualquier hombre necesitado con independencia de su status y nacionalidad. Desde el siglo IV d.C. la Iglesia tiende hacia su ecumenismo. En paralelo a este fenómeno, la pobreza se universaliza. Las causas pías transcienden el concepto de estatus ciudadano y abrazan a cualquier hombre pobre que siga a la religión cristiana universal. Es cierto, como ha sostenido G. E. Gardner que "the remaigining of society along economic lines, whereby individuals were identified as rich or poor, would have to wait until the fourth century"79. A los ojos de Dios, todos los hombres sufren la pobreza por igual. Es por ello, que los instituyentes de actividades fundacionales cristianas (testador, legatario, donatario, fideicomisario, etc.) del siglo IV d. C., V d. C. y VI d. C. se hacen progresivamente ecuménicos y protegen a todos los hombres cristianos pobres con independencia de su nacionalidad. A cambio, aquéllos logran la salvación perpetua de su alma.

Sin embargo, los Dioses clásicos y el Dios Cristiano conviven largo tiempo en el Bajo Imperio. Así lo creen C. Mango ${ }^{80}$ y G. W. Bowersock. Este último, además, sostiene que "when the emperor Constantine converted to Christianity into a Christian state, it long remained obvious thath the gods and cults of paganism did not simply dissappear. The new government made efforts over the following decades to close down the old temples, but their religión ans its mythology were far too deeply rooted to be plucked out and discarded"81. De la misma forma, a pesar de los esfuerzos oficiales, las actividades fundacionales posclásicas no suponen un desconocimiento ni una ruptura histórica con las actividades fundacionales clásicas. Por el contrario, las actividades de las fundaciones clásicas se prolongan a la epoca postclásica. Incluso nutren con sus esquemas jurídicos y conviven con las fundaciones cristianas del Bajo Imperio. Aunque, es evidente, que existió una verdadera evolución jurídica fundacional que se desarrolla progresivamente entre ambas etapas.

En esta dirección, aunque B. Santalucia cree que las instituciones de beneficencia no fueron desconocidas totalmente en los primeros siglos d.C. ${ }^{82}$, nosotros pensamos, por el contrario, que en la época clásica aquéllas fueron muy frecuentes. Así fueron muy intensas tanto las actividades fundacionales públicas como las actividades fundacionales privadas, según los casos, que fueron creadas por el Estado y los ciudadanos romanos y que fueron destinadas al mantenimiento y la construcción de obras públicas ${ }^{83}$ (termas,

\footnotetext{
78 En este sentido, Biondi B., "Il diritto romano cristiano", vol II, 1952, p. 176 ss.

79 Gadner G. E., "The Origins of Organizated Charity ...", cit. p. 10.

80 Mango C. "L'attitude byzantine à l'égard des antiquités gréco - romaines, Byzance et les images", París, 1994, pp. $95-120$.

81 Bowersock G. "Recapturing the Past...", cit. p. 3.

82 Santalucia, B. cit. p. 779.

83 D. 30.122. Paulus libro tertio regularum.
} 
baños, gimnasios, estadios ${ }^{84}$ foros $^{85}$ teatros $^{86}$ y representaciones escénicas ${ }^{87}$, puentes, acueductos, cloacas, depósitos y embalses de agua ${ }^{88}$, fuentes, templos y vías ${ }^{89}$, etc.), a la condonación permanente de impuestos ${ }^{90}$, a las ayudas solidarias frente a catástrofes en beneficio de la colectividad ${ }^{91}$, a la celebración de banquetes ${ }^{92}$, los juegos ${ }^{93}$ y los espectáculos ${ }^{94}$ (luchas de gladiadores, olimpiadas, representaciones teatrales) ${ }^{95}$, así como a la alimentación ${ }^{96}$ (alimenta), vestido, educación e instrucción de niños y niñas pobres, en el seno de sus familias humildes o, incluso bajo tutela dativa de terceros, y también a la protección de los débiles por su edad, por ejemplo, los adultos pobres y ancianos sin recursos para el honor colectivo de la ciudad ${ }^{97}$. En el Bajo Imperio cristiano, las donaciones, las disposiciones testamentarias, los legados, los fideicomisos privados y las aportaciones públicas, que provienen en su mayor parte de la parte oriental del Imperio (tal vez, como justamente ha sido puesto de relieve por B. Santalucia, por la grave crisis económica que sufrió la parte occidental durante los siglos III y IV d. C. ${ }^{98}$ ) dan continuidad a los fines fundacionales clásicos. Actividades colectivas perpetuas, sin ánimo de lucro, que prosiguen el mismo curso en el Imperio bizantino. En este sentido, el Emperador Justiniano regularizó por ley todas las donaciones, las disposiciones testamentarias y los legados que hubiesen sido instituidos para el desarrollo de actividades fundacionales pías, públicas y privadas, destinadas al cuidado y la nutrición de niños huérfanos, de los pobres, de los ancianos, de los enfermos, así como para la redención de cautivos, sujetos a prisión de guerra:

Si quis autem etiam pro redemptione captivorum aut alimentis pauperum hereditatem aut legatum reliquerit in rebus mobilibus aut inmobilibus, sive semel seu annale, et hoc modis omnibus secundum testatoris voluntatem ab his quibus iussum est hoc facere compleri, (545 d.C). ${ }^{99}$

En esta evolución histórica, desaparecen las motivaciones finales de las fundaciones clásicas, como el interés de Estado, el honor colectivo de la ciudad ${ }^{100}$, la gloria del ciudadano, el interés y el ornato de un municipio. La gloria, la humanitas y la aeternitas laicas clásicas se sustituyen por nuevas motivaciones filantrópicas posclásicas: la misericordia, la piedad, la caridad y la humanitas que debe prestar la Iglesia Cristiana

\footnotetext{
84 D. 30.122. Paulus libro tertio regularum.

85 D. 30.122. Paulus libro tertio regularum.

86 D. 30.122. Paulus libro tertio regularum.

87 D. 30.122. Paulus libro tertio regularum.

88 Byrnes W.H., "Ancient Roman Munificience: The Development of the Practice and Law Charity", en vol. 57 Rutgers Law Review 1043 (2005) p. 1083, available at http://ssrn.com/abstract=2314731

89 Byrnes W.H., "Ancient Roman Munificience: The Development of the Practice...", cit. (2005) p. 1082.

90 Byrnes W.H., "Ancient Roman Munificience: The Development of the Practice...", cit. (2005) p. 1088

91 Byrnes W.H., "Ancient Roman Munificience: The Development of the Practice...", cit. (2005) p. 1088.

92 Plinio, Epistolae, 7.18. C.I.L.10.1.5809. C.I.L.10.1.6483. C.I.L.11.2.47.89. C.I.L. 14.2827. D. 30.122. Paulus libro tertio regularum.

93 D. 30.122. Paulus libro tertio regularum.

94 C.I.L.8.2.9052. C.I.L.11.2.6377. D. 30.122. Paulus libro tertio regularum.

95 D. 30.122. Paulus libro tertio regularum.

96 C.I.L. 2.1174. C.I.L. 10.1.6328.

97 D. 30.122. Paulus libro tertio regularum.

98 Este es el parecer de Santalucia, B. cit. p. 779.

99 Nov. 131.11.

100 D. 30.122. Paulus libro tertio regularum.
} 
a todos sus fieles pobres. Causas que, a menudo, coinciden con el nuevo interés del Estado romano cristiano y de su emperador ${ }^{101}$. Actividades misericordiosas de caridad (caritas) que aquéllos asumen como propias.

En definitiva, asistimos a la evolución de la filantropía y de la humanitas clásicas, valores que significan amor por el hombre y la humanidad, circunscritas al officium pietatis de los ciudadanos romanos, a una nueva humanitas et caritas cristianas que surgen de la compasión por amor al prójimo de carácter universal. Nuevas obligaciones y fines postclásicos por y para causas pías (piae causae). Obligaciones de los fundadores, que sin embargo, no constituyeron causas de obligaciones civiles, pero sí, tal vez, causas de obligaciones de fe. El cristiano da y recibe de la Iglesia. Dona bienes y dinero. Recibe y gana el cielo (do ut des). El creyente destina su patrimonio a fines piadosos, pero obtiene, a cambio, su inmortalidad, mediante la resurrección de todos los fieles en Cristo. Con todo, un fin similar era perseguido por las actividades fundacionales públicas clásicas instituidas por los emperadores: la inmortalidad. Sin embargo, esta última era concebida como aeternitas romana, es decir, perpetuación del príncipe en la memoria de colectiva de los ciudadanos. Inmortalidad y gloria por sus actuaciones filantrópicas (ut ex indulgentia optimi maximique principis) ${ }^{102}$ realizadas en nombre del interés y del honor del Estado, incluso, de sus entes municipales ${ }^{103}$. Con todo, este nuevo fenómeno religioso cristiano fue de una vital transcendencia histórica y jurídica, por su carácter transformador de la naturaleza y de los fines fundacionales. Ahora, cristianos y universales. Acontecimiento calificado, de modo significativo, por W. H. Byrnes como "the birth of western legal charity". ${ }^{104}$

\section{El problema de la naturaleza jurídica de las fundaciones filantrópicas institucionales públicas de la Iglesia}

Los cambios históricos suelen ser lentos y progresivos. En la edad posclásica se produjo una transferencia del poder de Occidente a Oriente y una profunda transformación de las entrañas y de la naturaleza jurídica del Estado. De Imperio laico a Imperio cristiano. Esta óptica jurídica evolutiva también repercutió en la jovencísima Iglesia Cristiana. Esta última se venía organizando, ya desde el periodo clásico, en numerosas y diferentes asambleas territoriales de fieles. Estos círculos y agrupaciones (Ekklesiae) constituyeron uno de los varios pilares materiales que sirvieron para que el Derecho Público romano pudiese reconocer progresivamente a la Iglesia Cristiana como corpus ad exemplum rei publicae, es decir, como una entidad jurídica que se va emancipando poco a poco de sus propios fieles. En este sentido se posiciona J.L. Murga, quien sostiene que la idea de la Iglesia estaría mucho más cerca de una concepción municipal clásica que de un planteamiento universal ad instar populi Romani (...)". Así, según este autor "se trata de una iglesia localizada y comunitaria dándose en esta configuración un notable parecido y similitud con la idea colectiva de municipio"105. Sin embargo, este reconocimiento no parecía ser una novedad jurídica para las confesiones religiosas, pues, según reporta W.L Burdick, ya en tiempos tempranos "there were various

\footnotetext{
101 CJ.1.2.12.2. Valentinianus et Marcianus A.A. Palladio P.P. (451 d. C.). 102 CIL.XI, n.1147 EX TABULA OBLIGATIONIS PRAEDIORUM VELEIATE.

103 D. 30.122. Paulus libro tertio regularum.

104 Byrnes W.H., "Ancient Roman Munificience: The Development of the Practice...", cit. (2005) p. 1098.

105 Murga J.L. "La continuidad post mortem de la fundación cristiana y la teoría de la personalidad jurídica colectiva", en AHDE 38 (1968) pp. 496 - 497.
} 
collegia of priest connected with Roman temples, and, as previously stated, they were probably the oldest of all such bodies in Rome"106. Información que es acorde con la normativa jurídica que ya había sido reportada por Ulpiano en los inicios el siglo III d. C. Así, según sostiene este jurista, a algunas de aquellas corporaciones religiosas clásicas les había sido concedido por senadoconsulto y constituciones de los príncipes el derecho de poder recibir herencias mediante testamentos en los que se hubiese instituido herederos a sus dioses:

Deos heredes instituere non possumus praeter eos, quos senatus consulto constituionibusve principum instituere concessum est, sicuti Iovem Tarpeium. Apollinem Didymaeum Mileti, Martem in Gallia, Dianam Ephesiam (...) ${ }^{107}$

Por su parte, la nueva Iglesia Cristiana aspiraba no sólo a gozar del mismo estatus jurídico del que habían venido gozando algunas corporaciones religiosas en la etapa clásica, sino también a sustituirlas y desplazarlas progresivamente como nueva y única religión de Roma y del Imperio. En esta dirección, otro soporte decisivo, que unido a las asambleas de fieles, propiciará su nuevo reconocimiento como ente colegiado corporativo público fue, sin duda, la financiación de la Iglesia Cristiana por el Estado. Ya desde la República, las ciudades, los municipios y las colonias ${ }^{108}$ se nutrían con el dinero de los impuestos y de los tributos (vectigales). De la misma forma, en la época postclásica, la Iglesia como entidad que forma parte, y es protegida, del Estado recibirá de los emperadores numerosos privilegios ${ }^{109}$, una constante e importante financiación pública, bonificaciones fiscales, e, incluso, la exención del pago de impuestos ${ }^{110}$. De este modo, la Iglesia logra posicionarse en una posición pública de preeminencia, e insertarse entre los nuevos entes corporativos públicos del gobierno imperial que captan y administran fondos tributarios del Estado. Este nuevo estatus jurídico facultó a la Iglesia para nutrirse no sólo de financiación privada (mediante legados y donaciones) sino también de patrimonio público, subvenciones y rentas fiscales (vectigales). El manejo, la administración, y el control del dinero público hicieron que la Iglesia se fuese haciendo progresivamente acreedora al título jurídico (nacido en los últimos tiempos de la República) de corpus $^{111}$. En la misma línea de pensamiento jurídico se situó W. L. Burdick. Este último, desde la óptica de los derechos reales, relacionó directamente el nacimiento de la noción de corporación con el concepto de dominio público, pues sostuvo que "the roman doctrine of a corporation originated with the need or practical theory concerning the ownership of public property (...) the property of a municipality, a municipium (...) Consequently the original notion of a corporation in Roman Law was what we would call a municipal, or a public, corporation, and not a private

\footnotetext{
106 Burdick W.L., "The Principles of Roman Law and their relation to Modern Law", 1938, reimpresión New Jersey 2004, p.294.

107 Ulp. Reg. 22.6.

108 Burdick W.L., "The Principles of Roman Law ...", cit. p.280 : "The development of Rome's system of goverment, a goverment of states (civitates), municipalities (municipia), colonies (coloniae), and villages or districts (vici), that, as far as Rome is concerned, the idea of a corporation was born".

109 Los privilegios de las Iglesias de la religión cristiana ortodoxa son confirmados por Valentiniano y Marciano en el año 452 d. C. C.1.2.12.

110 CJ.1.2.8. Theodosius A. Isidoro P.P. Illyrici (424 d. C.).

111 Cicerón, Sest. 14.32. "nulla Romae societas vectigalium, nullum collegium aut concilium".
} 
corporation" 112 . De esta forma, el concepto de corporación pública (body corporate = universitas) fue conformado no sólo por un conjunto o una agregación sucesiva de ciudadanos, sino también por la capacidad de tener y administrar un patrimonio y dinero público.

Este desarrollo evolutivo ${ }^{113}$ que tiene por objeto el concepto jurídico de corporación es recepcionado primeramente por Constantino, quien lo utiliza para extenderlo a la joven e incipiente Iglesia. El emperador ordena que sean válidas las disposiciones de última voluntad realizadas de cualquier forma, siempre que el beneficiario sea "sanctissimo catholico venerabilique concilio" ${ }^{114}$. El concepto jurídico clásico de corpora (= concilio venerable), como órgano, o ente colegiado, dotado de patrimonio, corre por las venas de esta constitución imperial del año 321 d. C. ${ }^{115}$.

De esta forma, la Iglesia se va a ir forjando mediante una estructura jurídica colegialorganizativa de gobierno, compuesta de fieles y patrimonio, es decir, como corpus (concepto heredado, sin duda, del Derecho clásico romano). Molde jurídico con patrones religiosos, según reporta la Primera Carta de San Pablo a los Corintios: "los fieles de la Iglesia de Corinto se santifican en Cristo Jesús" ${ }^{116}$. Patrón, que, además, fue adoptado válidamente por Tertuliano, quien lo adoptó para su inserción en la joven Iglesia Cristiana de finales del siglo II d. C. y de los comienzos del siglo III d. C.: "Cum probi cum boni coeunt cum pii cum casti congregantur, non est factio dicenda, sed curia"117. Tertuliano identificó a la Iglesia con una congregación (corpus) de fieles que están unidos en el conocimiento de un Dios, con la unión de una doctrina y con la confederación de una esperanza ${ }^{118}$. Molde jurídico que, de la misma forma, fue extendida a los entes dependientes fundacionales, que fueron tutelados por aquélla.

Recepción jurídica que se mantendrá con oscilaciones en los primeros siglos del Bajo Imperio y, que culminará, sin duda, con su aceptación definitiva por los juristas y por el propio emperador Justiniano en el siglo VI d.C. En efecto, fruto de esta clara continuidad histórica del concepto jurídico clásico de corpus ad exemplum Reipublicae, y de su permanencia en la línea evolutiva histórica y jurídica del Imperio, la Iglesia y sus entes filantrópicos van a ir recibiendo, a través de sucesivas constituciones dictadas por los príncipes del siglo IV d. C., del siglo V d. C. y por los emperadores de la etapa bizantina del siglo VI d. C., la autorización pública del Estado para configurarse y actuar con un patrón jurídico corporativo. Este título facultó a las Iglesias y a sus entes dependientes para adquirir paulatinamente distintas facultades y derechos de la personalidad $^{119}$. Derechos y obligaciones de los que ya venían gozando, además del propio Estado, las ciudades, los entes municipales, algunas de las grandes corporaciones

\footnotetext{
112 Burdick W.L., "The Principles of Roman Law ...", cit. pp. 281 y 282.

113 Burdick W.L., "The Principles of Roman Law...", cit. p. 287: "the Roman idea of a municipal corporation (..) was an evolution".

114 CJ.1.2.1. Constantino A. ad populum.

115 Cicerón, Sest. 14.32. "nulla Romae societas vectigalium, nullum collegium aut concilium". En este sentido, Burdick W.L., "The Principles of Roman Law...", cit. p. 285, quien sostiene que "In fact, collegium is the oldest term for an association, being originally employed to designate both religious and trade associations. The later use of the word collegium is largely responsible, doubtless, for the opinión that a collegium in the early days of Rome was a corporation".

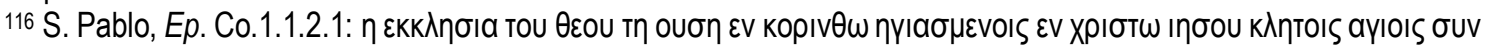

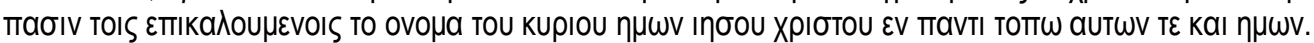

117 Tertuliano, Apologeticum, cp. 39.1.

118 Tertuliano, Apologeticum, cp. 39.1.

${ }_{119}$ C.J.1.2.19. C.J.1.2.22. C.J.8.53 (54) 34. CJ.1.2.23. CJ.1.3.45 (46). C.J.1.3.48, 3 -7. C.J.1.3.55 (57)4. Nov.120.6.
} 
empresariales de publicanos (vectigalium publicorum socius) ${ }^{120}$ y algunos de los colegios religiosos del mundo clásico. Tal vez, es por ello, que J. Frau ha sostenido que no sólo el Cristianismo se ha organizado sobre los pilares de lo que él denomina "the Roman Corporate Law", sino también, incluso, que la idea teológica que afirma que el Corpus Christi es el Cuerpo místico de Cristo, no es más que la aceptación por la Iglesia del modelo romano de corporación empresarial ${ }^{121}$. Sin embargo, esta tesis no nos parece sostenible, puesto que, desde finales de la República, las sociedades industriales de rentas públicas, que explotaban el vectigal, aunque adoptaron, por concesión jurídica soberana del poder público, un patrón corporativo, ya, previamente, este último había sido otorgado y aceptado por las ciudades y los municipios del Imperio. Entes territoriales y administrativos que se configuraron como espejos del Estado ad exemplum Reipublicae $^{122}$. Además, por lo que respecta a las fundaciones cristianas del Bajo Imperio, debemos añadir que, a diferencia de las grandes corporaciones de empresariales de publicanos, siempre el fin de aquéllas (elemento que tipifica y nutre la naturaleza jurídica de éstas) se caracterizó por ser un fin permanente de beneficiencia sin ánimo de lucro.

En este nuevo contexto histórico del siglo IV d. C., que posibilitó el progreso Cristiano, la Iglesia Ortodoxa, en clara alianza con el Estado imperial, creó numerosas entidades ${ }^{123}$ dedicadas a cumplir fines de culto. Entidades cristianas que se situaban también bajo la tutela jurídica y económica permanente de aquél. Florecen, así, los monasterios, los conventos y los templos que se diseminan por todos los territorios de influencia del Imperio. A la par, este fenómeno expansivo proselitista cristiano, greco oriental, permitió el nacimiento de nuevas entidades jurídicas cristianas dedicadas a funciones de caridad, sin ánimo de lucro ${ }^{124}$. Instituciones fundacionales filantrópicas permanentes de causas pías, que nacieron al abrigo de catedrales y monasterios ${ }^{125}$, y que estuvieron directamente relacionadas con la alimentación (alimenta) de los más desfavorecidos: hospitales (nosocomia), hospicios para pobres (ptochia, ptochos+ trophos $=$ pobres + sustento) (xenododochia), orfanatos (orphanotrophia, orphans + trophos $=$ niños + nutrición), casas para niños abandonados (brephotropia, brephos + trophos, niños expósitos + nutrición) y asilos para ancianos (gerontocomia). Instituciones cristianas que en el siglo V d. C. y en el siglo VI d. C., "were established at Rome, Alexandria, Antioch and Constantinople" ${ }^{26}$, para la asistencia de los indigentes y de los enfermos graves. Acontecimiento histórico importante. Incluso para la óptica jurídica, pues según sostiene G. Impallomeni, sobre estas instituciones se crearon los principios que están "alla base del concetto di fondazione"127. Instituciones, que en la etapa del Emperador Justiniano, según piensa P. W. Duff, constituyen "foundations itself" 128. Todavía más allá se posiciona Alvin J. Scmidt, quien sostiene, además, que estas

120 D.3.4.1. Gaius libro III ad Edictum provinciale. D.3.4.1.1. Gaius libro III ad Edictum provinciale 121 Faur J. "The Horizontal Society: Understanding the Conveniant and Alphabhetic Judaims", Boston, 2008, p.178. 122 D.3.4.1.1. Gaius libro III ad Edictum provinciale.

123 En este sentido, Schmidt A.J. "How Christianity changed the World", Zondervan Publishing House, ed. 2001, reimpresión 2009, Michigan., p. 125: "orphanotrophia (...) institutional structures that took parentless children from infancy on up".

124 Miller S.T. cit. p.67: "Just like orphanages, medical hospitals and hospices has emerged as new Cristians instituions in the fourth century", p. 67.

125 Schmidt A.J., "How Christianity changed (...)", cit., pp. 1, y125 ss.

126 Mundell Mango M., "The Cambridge Ancient History. Late Antiquity: Empire and Sucessors, AD. 425 - 600" vol. XIV, Cambridge University Press, edited A. Cameron, B. Ward - Perkins y M. Whitby (2008) p. 194.

127 Impallomeni G. cit p. 1032.

128 Duff P.W. "Personality in Roman Private Law", Cambridge University Press, 1938, p. 205. 
instituciones de caridad cristianas fueron fruto y forman parte del gran proceso de "how Christianity changed the World". ${ }^{129}$

En este escenario histórico jurídico de cambio, favorecido por los notables esfuerzos legislativos del poder público imperial, la Iglesia y el Estado canalizan las donaciones inter vivos y las disposiciones testamentarias (legados y fideicomisos privadas) hacia las nuevas instituciones de caridad públicas. Se produce así un fenómeno, o al menos un intento de concentración monopolístico fundacional posclásico en beneficio de las fundaciones públicas pías, en claro detrimento de las de fundaciones públicas y privadas laicas, de corte clásico. Cambio de orientación que va empapando progresivamente a los ciudadanos romanos y que también fue propiciado tanto por la Iglesia como por el Estado. En este sentido, W. H. Byrnes sostiene que "some believe a foundation ad pia causae could be created through a will, which would then be viable to inherit a state property personam. Of the organizations able to become pia causa were churches, monasteries, hospitals, and poor-houses" ${ }^{130}$. Es por ello, que desde sus inicios, y de acuerdo con las nuevas líneas pastorales cristianas, las entidades de caridad fueron vehículos sin ánimo de lucro que proporcionaban la salvación de las almas de sus mecenas y de sus protectores. Los emperadores, los magistrados y los altos funcionarios del Estado, de las ciudades y de los grandes municipios concurrieron al auge, el éxito y la protección de aquéllas en la parte oriental del Imperio, y al desplazamiento no solo de las fundaciones públicas laicas sino también al de las fundaciones privadas en interés del propio Estado y de sus entes dependientes, incluso, de la familia del propio instituyente.

En este nuevo e inédito contexto, las jóvenes instituciones de caridad cristianas se posicionan como nuevos entes receptores de patrimonio privado y público. Es por ello que, desde un punto de vista jurídico, surge el problema, conocido por la doctrina, de la llamada personificación de las instituciones fundacionales posclásicas, que fueron destinadas a dar cumplimento a causas pías de beneficencia. Es por ello, que según reporta W.L. Burdick "such charitable gifts are sometimes spoken of as subjects of rights, and as persons, and even corporations". ${ }^{131}$

Un sector doctrinal trata de dar solución a este problema con la tesis que propugna que las fundaciones públicas cristianas fueron personificándose sobre una base topográfica. Es por ello, que, según esta teoría, el edificio sería la base patrimonial sobre la que la fundación nace, se desarrolla como ente (universitas rerum) y adquiere, mediante sucesivas disposiciones legislativas imperiales, derechos y obligaciones. Esta solución jurídica (muy aceptada en la actualidad) fue formulada por Orestano ${ }^{132} \mathrm{y}$, según este autor, encuentra acomodo en una Novela de Justiniano:

Illud igitur ante alia dicendum est, ut omni tempore et in omni terra nostra, si quis aedificare venerabile monasterium voluerit, non prius licentiam esse hoc agendi, quam deo amabilem locorum episcopum

\footnotetext{
129 Schmidt A.J., "How Christianity changed the World", cit. p. 125 ss.

130 Byrnes W.H., "Ancient Roman Munificience...", cit. p. 1100.

131 Burdick W.L., "The Principles of Roman Law ...", cit. p. 295.

132 Orestano R., "Beni dei monaci e Monasteri nella Legislazione Giustinianea", en Studi in Onore di Pietro di Francisci, vol, III, 1956, pp. 563 - 590. Fabbrini F., "La personalità giuridica degli enti di asistenta (detti piae causae) in diritto romano", en T. bertone - O. Bucci, "La persona giuridica collegiale in diritto romano e canonico". Aequitas Romana et Aequitas canonica: atti del III Colloquio (Roma 24-26 aprile 1980) e del IV Coloquio (Roma 13-14 maggio 1981) Diritto romano - Diritto Canonico, Città del Vaticano, Roma, 1990, pp. 73 - 79. Blanch Nougués J.N., "La responsabilidad de los administradores de las piae causae", en RIDA n. 49, 2002, p 132. Otaduy J., "La universitas rerum como soporte de la personalidad en el derecho canónico", en lus Canonicum, vol 55, 2015, pp. 54 -56.
} 
advocet, at ille manus extendat ad caelum et per orationem locum consecret deo, figens in eo nostrae salutis signum (dicimus autem adorandam et honorandam vere crucem), sicque incohet aedificium, bonum utique quoddam hoc et decens fundamentum ponens. Hoc itaque principium piae venerabilium monasteriorum fabricae fiat. ${ }^{133}$

Sin embargo, a priori la constitución lo que parece establecer es el modo de transformar jurídicamente un edificio laico en uno religioso. Así, ordena la Novela que cuando se desee fundar un monasterio, antes de que éste inicie su andadura, el obispo tiene que consagrar a Dios el nuevo inmueble construido. A tal fin, aquél extendiendo las manos al cielo, ora y consagra y entrega un nuevo lugar a Dios para el cumplimiento de sus fines cristianos. La ley regula un ceremonial religioso cristiano. Por ello, creemos que la norma sirvió para situar a un inmueble fuera del comercio de los hombres y para afectarlo, como res sacra, tanto para fines espirituales religiosos cristianos como para la consecución de obras y causas pías: “(...) hoc itaque principium piae venerabilium monasteriorum fabricae fiat". ${ }^{34}$

A tenor de la Novela, no parece que Justiniano haya establecido expresamente una personificación geodésica o de corte topográfico de estos entes piadosos y de caridad, y menos aún que haya tomado para este fin, como base jurídica, el edificio que alberga a estas organizaciones religiosas. Este proceso de afectación religiosa del edificio a los fines de Dios y de sus obras pías se debía concretar a través de algún molde jurídico. Es posible que el edificio del monasterio y sus bienes raíces, así como los inmuebles de otros entes filantrópicos cristianos (edificios de hospitales, hospicios, orfanatos, asilos, etc.) fuesen estimados como parte del patrimonio del ente fundacional corporativo y consituyesen, además, los símbolos exteriores de éste. Es por ello que estimamos que los edificios no fueron considerados entes corporativos fundacionales personificados en sí mismos. El fenómeno parece ser bastante más complejo. El propio emperador Justiniano, en el año 529 de C. parece alejarse, si es que alguna vez la tuvo, de esta concepción jurídica topográfica, pues estableció mediante una constitución imperial que tanto la Iglesia como sus entes de caridad pueden organizarse como consorcios destinados a dar cumplimiento de fines fundacionales píos:

Sancimus res ad venerabiles ecclesias vel xenones vel monasteria vel ptochotrophia vel brephotrophia vel orphanotrophia vel gerontocomia vel si quid aliud tale consortium descendentes ex qualicumque curiali liberalitate sive inter vivos sive mortis causa sive in ultimis voluntatibus habita lucrativorum inscriptionibus liberas immunesque esse: lege scilicet, quae super huiusmodi inscriptionibus posita est, in aliis quidem personis suum robur obtinente, in parte autem ecclesiastica vel aliarum domuum, quae piis consortiis deputatae sunt, suum vigorem pietatis intuitu mitigante. Cum enim non faciamus discrimen inter res divinas et humanas, et quare non competens praerogativa caelesti favori conservetur? ${ }^{135}$

En el concepto de organización jurídica asociativa para fines de piedad está implícito, sin duda, la idea de corpus como ente jurídico del que disfrutan las venerabiles

133 Nov. 5.1.

134 Nov. 5.1.

135 CJ.1.2.22. 
ecclessias y sus entes destinados a causas pías. Aunque L. Pepe piensa que existe contraposición entre Iglesia y consortium piis "e che le relative case si riferiscono a due tipologie di soggetti diversi" ${ }^{136}$, es claro que el Emperador los inserta de forma copulativa en su constitución. Todos se nutren de la misma naturaleza jurídica:

(...) vel xenones vel monasteria vel ptochotrophia vel brephotrophia vel orphanotrophia vel gerontocomia vel si quid aliud tale consortium descendentes (...) in parte autem eclesiástica vel aliarum domuum, quae piis consortiis deputatae sunt. ${ }^{137}$

Incluso el Emperador va más allá, pues también en el año 529 d. C., sitúa a la Iglesia y a sus entes fundacionales unidos a las ciudades, y sostiene, además, que todos ellos pueden ser beneficiarios de donaciones privadas para el desarrollo de sus causas pías y de sus fines cristianos de utilidad general:

Illud, quod ex veteribus legibus licet obscure positis a quibusdam attemptabatur, ut donationes super piis causis factae, licet minus in actis intimatae sint, tamen valeant, certo et dilucido iure taxamus, ut in aliis quidem casibus vetera iura super intimandis donationibus intacta maneant: si quis vero donationes usque ad quingentos solidos in quibuscumque rebus fecerit vel in sanctam ecclesiam vel in xenodochium vel in nosocomium vel in orphanotrophium vel in ptochotrophium vel in ipsos pauperes vel in quamcumque civitatem, istae donationes etiam citra actorum confectionem convalescant: sin vero amplioris quantitatis donatio sit, excepta scilicet imperiali donatione, non aliter valeat, nisi actis intimata fuerit: nulli danda licentia quacumque alia causa quasi pietatis iure subnixa praeter eas, quas specialiter exposuimus, introducenda veterum scita super intimandis donationibus permutare. ${ }^{138}$

En esta dirección, W.W. Buckland y A.D. MCnair creen que la recepción de obsequios, regalos y donativos debió ser el comienzo, o un punto de partida para el reconocimiento jurídico de estas entidades como corpora: "charitable foundatios as corporate belong to the Cristian Empire. As with us, the starting point seems to have been gifts to churches, already recognised as corporate, for specified purposes" ${ }^{\prime 139}$. En esta línea jurídica se sitúa también G. Mousourakis, quien (tal vez, con el apoyo autorizado que ofrece la Nov. 131.6, 545 d.) llama la atención sobre la naturaleza jurídica de los entes fundacionales a los que califica de corporate charities. Así, según este autor, su posible institución testamentaria como personae incerta, ya en el Bajo Imperio, constituyó un verdadero método de financiación que benefició no solo al Estado y los municipios sino también a "the charitable institutions and other corporate bodies". Instituciones de herederos que eran realizadas por los instituyentes en favor de las fundaciones corporativas cristianas (corporate charities). Práctica que denota una visión personificada

136 Pepe L., "Latino e altri lingue nel tardo antico: qualche considerazione sulle "piae causae", en Fundamina (Pretoria) vol, 20.n.2, 2014, p. 681.

137 CJ.1.2.22.

138 CJ.1.2.19.

139 Buckland W.W. y MCnair. A., "Roman Law and Common Law: A Comparison in Outline". 1ª ed. 1936, reimpr.1952, pp. $57-58$. 
de los entes fundacionales por los testadores. Uso que culminó con su aceptación generalizada y por su reconocimiento oficial mediante el poder imperial de Justiniano ${ }^{140}$. Afirmación que, sin duda, encuentra sólidos apoyos en la Nov. 131.6, (545d.):

\begin{abstract}
Pro temporalibus autem praescriptionibus $X$ et $X X$ et $X X X$ annorum sacrosanctis ecclesiis et aliis universis venerabilibus locis solam quadraginta annorum praescriptionem opponi praecipimus; hoc ipsum servando et in exactione legatorum et hereditatum quae ad pias causas relictae sunt.
\end{abstract}

Es por ello que, probablemente, los emperadores del Bajo Imperio adoptaron paulatinamente el concepto jurídico de corpus e institucionalizaron a las entidades filantrópicas cristianas como cuerpos fundacionales públicos. De esta evolución jurídica parecen dar cuenta De Zulueta, WW. Buckland y Arnold D. Macnair, quienes advierten, además, que muchas donaciones, testamentos y legados patrimoniales píos fueron realizados en nombre de los obispos y de otros miembros de las altas jerarquías. Circunstancia que provocó una gran confusión entre el patrimonio fundacional y el patrimonio privado de los patriarcas y de los obispos ${ }^{141}$. Estos hechos vendrían a demostrar que probablemente las fundaciones cristianas del Estado bizantino y las fundaciones de las Iglesias Ortodoxas se organizaron corporativamente ad exemplum Reipublicae de un modo lento. Fundaciones que se vistieron lentamente de corporaciones y que fueron vinculadas perpetuamente al cumplimiento de fines inamovibles, píos y religiosos, sin ánimo de lucro (pia causa).

Al cumplimiento de tal fin, los emperadores del Bajo Imperio fueron amalgamando distintos elementos jurídicos clásicos, mediante diferentes y sucesivas constituciones, que posibilitaron la creación de las fundaciones públicas cristianas (corporate charities) como instituciones públicas permanentes:

a) La concesión por el Estado del título de corporación a las instituciones fundacionales, bien directamente, bien a través de la Iglesia, que hace surgir un ente público (corpora) autónomo cristiano con facultades de adquisición de derechos y obligaciones. En este sentido, tal como ha puesto de relieve R. B. Coser la necesidad de dar un reconocimiento legal al funcionamiento de grupos de personas (en la que el autor incluye la organización eclesiástica) fue desarrollado por el Derecho Romano "which fostered the idea thath corporate or legal groups could only come into existente by imperial fiat or the creative touch of sovereign power" 142 .

b) La posibilidad de una salida sin retorno del patrimonio del instituyente (público o privado) y su adquisición y titularidad definitiva por el ente corporativo fundacional filantrópico pío.

c) La creación y dotación de una organización interna corporativa. El consorcio directivo colegiado organizado representa y administra y obliga a a fundación cristiana frente a terceros.

\footnotetext{
140 Mousurakis G, "Roman Law and the Origins of the Civil Law Tradition", Ed. Springer, New Zealand (2015), p. 152 y nota 192: "Thus in Justinian's time it was possible to institute the State, the Church and religious or charitable organizations as heir".

${ }^{141}$ Buckland W.W. y MCnair. A., "Roman Law and Common Law: A Comparison ...", cit. p. 59.

142 Couser R.B., "Ministry and The American Legal System: A Guide for Clergy, Lay Workers, and Congregations", Minneapolis, 1993, p. 63.
} 
d) La vinculación perpetua de la fundación al cumplimiento a de la voluntad fundacional unilateral, sin ánimo de lucro (caritas), que haya sido establecida por el instituyente fundador, o los fundadores.

Estos resortes jurídicos son fruto de una larga evolución clásica que viene a culminar en el reconocimiento legislativo imperial de los diversos resortes jurídicos que configuraron a las instituciones bonum animae posclásicas. Es por ello que las fundaciones cristianas no son completamente originales. Se nutren de las raíces y de los elementos jurídicos que nutrían a las fundaciones del Alto Imperio clásico. Es por por ello que creemos que la legislación imperial no concibió a sus instituciones fundacionales de caridad sobre la base de una nueva concepción jurídica topográfica personificada ${ }^{143}$. De acuerdo con las constituciones imperiales del Bajo Imperio y de las Novelas de Justiniano, nos parece que, tal vez, la fundación fuese concebida paulatinamente como entidad institucional corporativa de caridad, que adoptó perfiles jurídicos prácticos antropomórficos, para poder dar así cumplimiento a sus fines sin ánimo de lucro y de causas pías. En consecuencia, creemos que la fundación fue percibida y perfilada por los emperadores posclásicos como corpus religioso ad exemplum Reipublicae Cristiana. ${ }^{144}$

Posteriormente, en la etapa justinianea, se reciben estos elementos y las fundaciones de la Iglesia, así como las fundaciones públicas mixtas Iglesia - Estado (la Iglesia Cristiana Ortodoxa oriental está sometida al Emperador) se constituyeron definitivamente como entes corporativos autónomos sin ánimo de lucro, dotados de patrimonio propio y tutelados por la legislación y el Derecho Público ${ }^{145}$. Así, en este sentido, P.W. Duff sostiene que "the only serious Roman evidence for such personification is the supposed use of pia causa to mean a Charitable Foundation, and we have shown above that the expression ist no used before, or by Justinian ${ }^{146}$ "..

Con todo, en el siglo VI d.C., el Estado y la Iglesia Ortodoxa deciden discrecionalmente sobre la conveniencia de crear fundaciones caritativas en cada momento. En su caso, el gobierno del Imperio, en numerosas ocasiones, autoriza y participa no sólo en su construcción, sino también en la vigilancia, proyección y composición de su estructura corporativa. Las fundaciones públicas cristianas se presentan así como instituciones estables con autogobierno organizado, pero dependientes de la Iglesia y del Estado. Este perfil de la fundación, como poder y como corporación pública y eclesiástica, se subraya de modo notorio por la fuerte intervención del Estado romano bizantino en su economía. Ya desde el siglo V d.C., este último es siempre considerado un importante inversor financiero por la propia Iglesia Ortodoxa y por sus entes fundacionales dependientes. Esta posición protectora del Estado es puesta

\footnotetext{
143 Tesis defendida por Feenstra R., "The Development of the Concept Foundation in Continental Law", 1971. Acta Juridica, p. 123. También, Murga J.L., "La continuidad post mortem de la fundación cristiana y la teoría de la personalidad jurídica colectiva", en AHDE, 1968, pp. 550 - 551: "Al descartarse, pues la colegiación, la vieja solución patrimonial, origen embrionario de estos hospitales, asilos y albergues, continúa manteniendo el centro de gravedad de la autonomía jurídica en el edificio personificado y haciendo de la casa el el eje de toda su actuación en la vida negocial. Sin embargo, esta especie de necesidad de materializar de algún modo a la persona jurídica, aunque sea en un edificio de piedra, está lo suficientemente enraizada en el espíritu humano para que no desaparezca rápidamente".

144 En sentido contrario, Impallomeni G. cit. p. 1032.

145 Miller S.T. cit. p. 177: "The clearest evidence that Zotikos's orphanage outranked all other charitable institutions come from the imperial legislation of the fifth century".

146 Duff P.W. "Personality in Roman Private ...", cit. p. 234.
} 
de relieve por Valentiniano y Marciano, quienes, mediante una constitución imperial se dirigen a Palladio (P.P., 451 d.C.):

Et quia humanitatis nostrae est prospicere egenis ac dare operam, ut pauperibus alimenta non desint, salaria etiam, quae sacrosanctis ecclesiis in diversis speciebus de publico hactenus ministrata sunt, iubemus nunc quoque inconcussa et a nullo prorsus imminuta praestari liberalitatique huic promptissimae perpetuam tribuimus firmitatem. ${ }^{147}$

Los Príncipes ordenan que las Iglesias cumplan, sin dilación, con los suministros anuales de alimenta, para beneficio de los más pobres y necesitados. Estos programas fundacionales, según la constitución imperial, son financiados anualmente con cargo al erario fiscal público. Por ello, aunque T.S. Miller ha sostenido que "the most striking innovation of Byzantine society was the establishment of Christian philanthropic institutions capable of accepting helpless infants and providing them with the nurture they needed in order to survive" 148 , sin embargo, de acuerdo con la normativa legal anterior de Valentiniano y Marciano, es evidente que estos últimos, y después los emperadores posclásicos, dan continuidad a las tradicionales actividades fundacionales públicas clásicas de concesión de alimenta a favor de los más necesitados. Sin embargo, ahora los programas fundacionales se realizan a través de instituciones cristianas de caridad permanentes y mediante continuos subsidios anuales (dinero público fiscal). De este modo, las ciudades (y su honor) ${ }^{149}$ son desplazadas directamente por las Iglesias ortodoxas del Estado imperial, pues estas últimas son las nuevas instituciones encargadas de cumplimiento de los nuevos fines misericordiosos cristianos. La norma imperial de Valentiniano y Marciano constata que los entes filantrópicos del siglo V d. C. reciben aportaciones tributarias, patrimoniales y en especie anuales públicas del Estado para el cumplimiento permanente de sus fines piadosos. En la misma dirección Justiniano, ya en los primeros decenios del siglo VI d. C., nos informa también de la existencia de numerosas inversiones fiscales anuales, que son realizadas por el propio Estado en favor de sus establecimientos cristianos de caridad:

(...) quae annalia vocant leges (...) quod in perpetuum relictum est venerabilibus domus, quibus praesunt, sive in auro, sive in aliis rebus, tentaverit permutare. ${ }^{150}$

En la misma dirección, Justiniano da noticias, además, de la existencia de otras donaciones dinerarias discrecionales que eran realizadas bien por los ciudadanos bien por las instituciones públicas imperiales en favor de los patrimonios de las instituciones fundacionales de caridad:

(...) si quis vero donationes usque ad quingentos solidos in quibuscumque rebus fecerit vel in sanctam ecclesiam vel in xenodochium vel in nosocomium vel in orphanotrophium vel in ptochotrophium vel in ipsos pauperes vel in quamcumque civitatem,

147 CJ.1.2.12.2. Valentinianus et Marcianus A.A. Palladio P.P. (451 d.C.).

148 Miller S.T. cit. p. 174.

149 D. 30.122. Paulus libro tertio regularum: "Hoc amplius quod in alimenta infirmae aetatis, puta senioribus vel pueris puellisque, relictum fuerit ad honorem civitatis pertinere respondetur".

150 CJ. 1.3.57 (55). Iustinianus A. Ioanni P.P. (534 d. C.). 
istae donationes etiam citra actorum confectionem convalescant sin vero amplioris quantitatis donatio sit, excepta scilicet imperiali donatione, non aliter valeat, nisi actis intimata fuerit: nulli danda licentia quacumque alia causa quasi pietatis iure subnixa praeter eas, quas specialiter exposuimus, introducenda veterum scita super intimandis donationibus permutare. ${ }^{151}$

En esta dirección, es relevante poner de relieve la información que nos reporta M. Mundell, quien sostiene que el Hospicio Sanson de Constantinopla (destruido en el año 532 d. C.) fue reconstruido por el propio emperador Justiniano. No lejos de esta institución sanitaria fundacional, su sucesor, Justino II edificó el orfanato de San Pablo ${ }^{152}$. Este venerable edificio fundacional cristiano fue de tanta envergadura y complejidad administrativa, que constituyó, según la escritora medieval Ánna Komnēné una "ciudad dentro de una ciudad"153. Es evidente, que los emperadores se irguieron en decididos creadores y protectores del patrimonio fundacional eclesiástico. Mecenazgo fundacional que, además, les legitimó para fiscalizar no sólo las cuentas y los inmuebles fundacionales religiosos - públicos, sino también todas las actuaciones de la jerarquía de las Iglesias y de los entes corporativos caritativos de las Venerables Casas. Las actividades de control y supervisión son reglamentadas por el propio Justiniano en algunas leyes y constituciones imperiales. Así, el Emperador se dirige a Juan, Prefecto del Pretorio (534 d. C.), y establece que ni los ecónomos de las Santísimas Iglesias, ni los prefectos de los hospitales puedan vender el patrimonio de los monasterios ni de sus entidades fundacionales filantrópicas, es decir, nosocomios, hospitales de peregrinos, hospicios de pobres, monasterios, o cualesquiera otra corporación de este tipo, "aut aliorum talium corporum". ${ }^{154}$

Este mandato legal hace aflorar la naturaleza corporativa de las fundaciones cristianas bizantinas. En esta línea de pensamiento jurídico, diez años mas tarde (544 d. C.), el propio Emperador pone de relieve otra vez, con una nueva constitución imperial, que estos entes corporativos públicos de caridad religiosa tienen su propia estructura organizativa interna, es decir, su propia administración autónoma que los dirigen y los representan frente a terceros: "si vero ptochia aut xenones aut nosocomia aut reliquae venerabiles domus sint propriam administrationem habentes" ${ }^{155}$. Extremo que es confirmado por T.S. Miller, quien afirma que también "the orphanotropheion evolved into such a complex administrative structure". ${ }^{156}$

Esta naturaleza corporativa fundacional mixta, Iglesia - Estado, se acentúa, además, si atendemos a la composición y a las funciones que realizaban los directores encargados de la gestión y administración de estas entidades. Así, según piensa T.S. Miller, los directores ejecutivos de las instituciones fundacionales cristianas (de la que sobresalen por su importancia los orfanatos y los hospitales ubicados en Constantinopla y en otras ciudades importantes del Imperio) pertenecen tanto a los rangos burocráticos más elevados del Estado imperial como a los oficios más elevados de la jerarquía de la Iglesia bizantina: "orphanotropheion, one must first consider its preminent position

151 CJ.1.2.19. Iustinianus A. Mennae P.P. (528 d.C.).

152 Mundell Mango M., "The Cambridge Ancient History...", cit. p. 194.



154 CJ. 1.3.57 (55). Iustinianus A. Ioanni P.P. (534 d. C.).

155 Nov. 120. cp. 6.1. (544 d. C.).

156 Miller S.T. cit. p. 176. 
among all other philanthropic institutions of the empire also the high rank that its directors enjoyed in both the church hierarchy and the state bureaucracy"157. Es por ello, que tanto el Estado como la Iglesia (patriarcas, obispos, arzopispos y metropolitanos de las provincias ${ }^{158}$ ) decidían sobre los nombramientos de sus patronos ejecutivos y tenían un poder de control sobre éstos y sus equipos de gobierno ${ }^{159}$ (ecónomos ${ }^{160}$, tesoreros, cartularios ${ }^{161}$, profesores, tutores ${ }^{162}$, etc.). Aquellos podían expulsar a los administradores de las fundaciones de caridad y nombrar a nuevos directivos y ministros para que asumiesen la dirección y la ejecución de los fines piadosos: “(...) administratione vero pessime gesta, etiam eos expellant, et alios instituant ${ }^{163 "}$ ". En este marco de competencias, no era infrecuente que el Prefecto del pretorio de Constantinopla enviase a sus agentes a los orfanatos para verificar el estado de sus patrimonios mediante la realización de inventarios. ${ }^{164}$

Con todo, G. Impallomeni piensa que los entes de beneficencia "non possono ritenersi corporazioni" 165 . Sin embargo, aquél cree que los monasterios sí constituyeron colegios religiosos "e per tanto capaci di diritto" 166 . Se debe poner de relieve ahora que desde la etapa de gobierno de Constantino, no sólo las Iglesias ortodoxas sino también los monasterios cumplieron misiones y fines perpetuos fundacionales para el desarrollo de causas pías. Los monasterios también otorgaron cuidado, nutrición y educación a niños pobres desamparados, a los huérfanos y a los niños abandonados. Además, prestaban asistencia a los ancianos enfermos y a los pobres adultos indigentes, enfermos y necesitados ${ }^{167}$. Posteriormente, las Iglesias y los monasterios ortodoxos bizantinos, de comienzos del siglo $\mathrm{V}$ d. C., siguieron con esta tradición cristiana filantrópica pía. Incluso, los monasterios contaban en el interior de sus recintos con instalaciones y patrimonios fundacionales permanentes: hospederías para pobres, orfanatos, asilos y colegios propios ${ }^{168}$. Esta situación explica que los monasterios fueran situados por el Emperador Justiniano en la misma línea jurídica que el resto de las instituciones corporativas fundacionales. En este sentido, es muy significativo también que en una constitución del año 534 d. C. (C.1.3. 57 (55)), el Emperador confirme de nuevo la naturaleza corporativa colegial tanto de los monasterios (ad exemplum rei publicae cristiana) como de las casas fundacionales pías: "venerabilibus vero domibus et earum congregationibus (...) quae inmortales a Deo conservantur" 169 . Colegios y congregaciones filantrópicas cristianas que no mueren nunca (= naturaleza jurídica de la Iglesia):

\footnotetext{
157 Miller S.T. cit. p. 177.

158 C.1.3.46 (45).3 - 6. Iustinianus a Iuliano P.P. (530 d.C).

159 Nov.131.11.4: "Si autem sanctissimus locorum episcopus reliquerit aliquid horum quae a nobis dicta sunt, liceat et sanctissimo eius metropolitae haec omnia exigere et complere, et omni alio licentia sit huiusmodi movere quaestionem et studere, ut modis omnibus causae piae compleantur", (545 d.C).

160 Nov.131.11.3 (545 d. C.).

161 Nov. 120 , cp. 5 - 6.

162 Miller S.T. cit. pp. 176 - 177.

163 C.1.3.46. (45) 3. Iustinianus a Iuliano P.P. (530 d.C.).

164 C.1.2.17. Anastasius. Miller S.T. cit. p. 75: "the orphanotrophoi were to prepare an inventary of the property of each orphan subject to them and accept the supervision of the property in the presence of agents representing the urban prefect of Constatinople".

165 Impallomeni G. cit. p. 1032.

166 Impallomeni G. cit. p. 1032.

167 Miller S.T. cit. p.67.

168 Miller S.T.cit. p.67.

${ }^{169}$ CJ. 1.3.57 (55). Iustinianus A. Ioanni P.P. (534 d. C.).
} 
Sed quoqusque utique permanserit venerabiles domus (manent autem in perpetuum et usque ad ipsum saecolurum finem, quousque Christianorum nomen apud homines erit et coletur). ${ }^{170}$ C):

Naturaleza jurídica colegial que es ratificada de nuevo por la Nov. 7, cp. 2 (535 d.

Et hoc valere volumus in omni ecclesia omnique monasterio et nosocomio et xenodochio et brephotrophio et asceterio et gerontocomio et omni absolute collegio quod actio pia constituit, nullo penitus horum aliquid accipere ab eis Valente".

Y por el cp. 9 de la Nov. 7 (535 d. C.):

"Sancimus nulli penitus licentiam esse talem quempiam pragmaticum proferre typum neque ex hoc accipere aliquid [de] sanctissimis ecclesiis competentium aut monasteriis aut ptochiis aut venerabilibus collegiis immobilium rerum".

En este periodo, a tenor de la legislación imperial, se configuran de modo permanente las fundaciones como entidades corporativas filantrópicas públicas, bizantinas, cristianas ${ }^{171}$, collegio quod actio pia constituit ${ }^{172}$ (colegios que son fundados para causas pías = corporate charities) . Entes jurídicos que gozan de autonomía jurídica, capacidad de obrar, facultad para la adquisición de bienes y la constitución de obligaciones y contratos ${ }^{173}$, capacidad de autoadministración y toma de decisiones jurídicas vinculantes en su nombre como instituciones filantrópicas, dirección corporativa mediante un administrador et omnium ministrorum gubernationis ${ }^{174}$, levantamiento de $\operatorname{actas}^{175}$, tesorería, contabilidad y autofinanciación propia (por ejemplo, mediante la explotación de fundos enfitéuticos fundacionales ${ }^{176}$ ). En último término, además, poder de litigar para la defensa de la voluntad unilateral establecida por el fundador ${ }^{177}$. Potestades propias de los ciudadanos, sujetos de derechos, que, desde la etapa clásica, fueron otorgadas por las leyes y las constituciones de los príncipes a las ciudades y

170 CJ. 1.3 .57 (55). Iustinianus A. Ioanni P.P. (534 d. C.).

171 Nov. 131.6: "Pro temporalibus autem praescriptionibus $X$ et $X X$ et $X X X$ annorum sacrosanctis ecclesiis et aliis universis venerabilibus locis solam quadraginta annorum praescriptionem opponi praecipimus; hoc ipsum servando et in exactione legatorum et hereditatum quae ad pias causas relictae sunt". Nov.131.11.3: "Si autem qui haec facere iussi sunt semel et secundo a beatissimo locorum episcopo aut huius oeconomis per publicas personas admoniti distulerint quae disposita sunt adimplere, iubemus eos omne lucrum relictum eis ab eo qui haec praecepit amittere, et locorum episcopos omnes res cunctis, sicuti dictum est, piis causis distributas cum fructibus et augmentis medii temporis et memorato lucro vindicare et quae testator disposuit adimplere, scientes quia, si neglexerint, pro his omnibus rationem deo persolvent". Nov.131.11.4: "Si autem sanctissimus locorum episcopus reliquerit aliquid horum quae a nobis dicta sunt, liceat et sanctissimo eius metropolitae haec omnia exigere et complere, et omni alio licentia sit huiusmodi movere quaestionem et studere, ut modis omnibus causae piae compleantur", (545 d.C).

172 Nov. 7. cp. 2. Nov. 7. cp. 6. Nov.7. cp. 9.

173 C.1.3.17. 1. Anastasius. Nov.7.cp.3.

174 C.1.3.17.1. Anastasius. C.1.3.46 (45).3. Iustininianus a Juliano (530 d.C.): "(...) piarum actionum administratores".

175 Nov. 7. cp. 1. Nov. 120. cp. $6-7$.

176 Nov. 7. cp. 2. Nov. 7. cp. 6. Nov.7. cp. 9.

177 C.1.2.19. C.1.2.22. C.1.2.23.C.1.3.45 (46). Nov.7.cp.5. 
corporaciones municipales ${ }^{178}$. Su existencia, todavía en época bizantina, no viene sino a confirmar la recepción del molde jurídico corporativo por las instituciones filantrópicas cristianas. La Iglesia Ortodoxa es el mayor espejo jurídico colegial corporativo cristiano del Imperio bizantino. Las Venerables Casas filantrópicas sus reflejos ${ }^{179}$. Aunque con sus propias especificidades, ambas se nutren perpetuamente tanto de las donaciones y de las aportaciones individuales de los fieles (patrimonio y dinero privado ${ }^{180}$, que, en numerosas ocasiones, tienen por destinatarios, como donatarios, herederos, legatarios, e incluso fideicomisarios a los Profetas ${ }^{181}$, los Ángeles ${ }^{182}$, los Santos y Jesucristo ${ }^{183}$ ) como de las donaciones y los réditos patrimoniales y tributarios del Estado (dinero público). Los emperadores bizantinos fueron siempre fieles mecenas poderosos de las Iglesias Ortodoxas y de sus Venerables Casas. Protectores sólidos y fiables del patrimonio cristiano filantrópico y del funcionamiento de los consejos de gobierno y administración corporativos. Estos últimos fueron los encargados de ejecutar las acciones para cumplir las voluntades inamovibles piadosas, sin ánimo de lucro, perpetuas y colectivas, que hubiesen sido establecidas: "aequum itidem est, manere et in perpetuum relictas erogationes aut reditus, inmortales semper piis actionibus numquam cessaturis

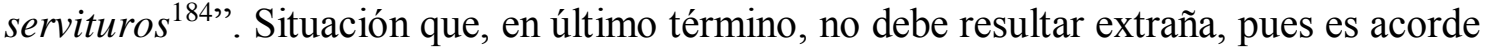
con la posición de preeminencia que siempre mantuvo el Estado bizantino sobre la Iglesia Ortodoxa. En este sentido, P. Stein reporta que Justiniano siempre mantuvo "que reunía en sí mismo no sólo el supremo poder temporal, expresado en la noción de imperium, sino también el supremo poder espiritual del sacerdotium". ${ }^{185}$

Recebido em: 22 de abril de 2016.

Aprovado em: 26 de maio de 2016.

178 D.3.4.1. Gaius libro III ad edictum provinciale. D. 3.4.1.1. Gaius libro III ad edictum provinciale. D.3.4.1.2. Gaius libro III ad edictum provinciale. D.3.4.1.3. Gaius libro III ad edictum provinciale. D.3.4.2. Ulpianus libro VIII ad edictum. D.3.4.3. Ulpianus libro IX ad edictum.D.3.4.6.3. Paulus libro IX ad edictum.D.3.4.7.1. Ulpianus libro $X$ ad edictum. D.3.4.8. lavolenus libro IX ex Cassio.

179 C.1.2.17. Anastasius: Privilegia magnae ecclesiae Constantinopoleos et sub ipsa administratarum et sustentatarum venerabilium domorum custodiuntor.

180 Nov. 131.6: "Pro temporalibus autem praescriptionibus $X$ et $X X$ et $X X X$ annorum sacrosanctis ecclesiis et aliis universis venerabilibus locis solam quadraginta annorum praescriptionem opponi praecipimus; hoc ipsum servando et in exactione legatorum et hereditatum quae ad pias causas relictae sunt", (545) d.C.

181 C.1.2.15. Zeno.

182 C.1.2.15. Zeno.

183 Burdick W.L., "The Principles of Roman Law ...", cit. p. 295. Murga Gener J.L. loc.cit. not 54, pp. 357- 419.

184 CJ. 1.3.57 (55). Iustinianus A. Ioanni P.P. (534 d. C.).

185 Stein P. "El Derecho Romano en la Historia de Europa", 1 edición 1999, reimpresión Madrid 2001, pp. 59 -60. 